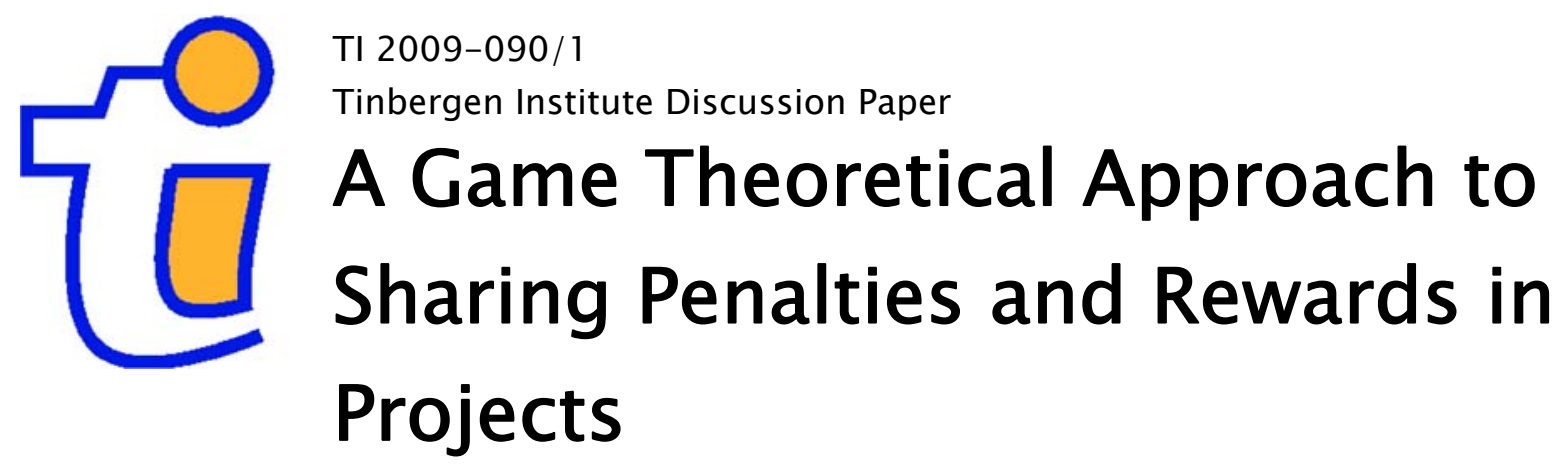

Arantza Estévez-Fernández 


\section{Tinbergen Institute}

The Tinbergen Institute is the institute for economic research of the Erasmus Universiteit Rotterdam, Universiteit van Amsterdam, and Vrije Universiteit Amsterdam.

Tinbergen Institute Amsterdam

Roetersstraat 31

1018 WB Amsterdam

The Netherlands

Tel.: +31(0)205513500

Fax: $+31(0) 205513555$

Tinbergen Institute Rotterdam

Burg. Oudlaan 50

3062 PA Rotterdam

The Netherlands

Tel.: + $31(0) 104088900$

Fax: $+31(0) 104089031$

Most TI discussion papers can be downloaded at http://www.tinbergen.nl. 


\title{
A game theoretical approach to sharing penalties and rewards in projects
}

\author{
Arantza Estévez-Fernández ${ }^{1}$
}

\begin{abstract}
:
This paper analyzes situations in which a project consisting of several activities is not realized according to plan. If the project is expedited, a reward arises. Analogously, a penalty arises if the project is delayed. This paper considers the case of arbitrary nondecreasing reward and penalty functions on the total expedition and delay, respectively. Attention is focused on how to divide the total reward (penalty) among the activities: the core of a corresponding cooperative project game determines a set of stable allocations of the total reward (penalty). In the definition of project games, surplus (cost) sharing mechanisms are used to take into account the specific characteristics of the reward (penalty) function at hand. It turns out that project games are related to bankruptcy and taxation games. This relation allows us to establish the nonemptiness of the core of project games.
\end{abstract}

Keywords: Project planning, delay, expedition, cost sharing mechanism, surplus sharing mechanism, bankruptcy problems, taxation problems, cooperative game, core.

JEL classification: C71, C44.

\section{Introduction}

A project consists of a set of activities, which interconnections are known, being completed over a period of time and intended to achieve a particular aim. The project time is the minimum time needed to end all the activities in a project.

Nowadays, many projects require employing and coordinating different companies to perform specialized jobs, like the creation of high technology devices, the construction of a building, and the construction of infrastructures (such as highways and railroads). Due to its high societal and economical relevance, project

\footnotetext{
${ }^{1}$ Department of Econometrics and Operations Research and Tinbergen Institute, VU University Amsterdam, De Boelelaan 1105, 1081HV Amsterdam, The Netherlands. E-mail address: mestevez@feweb.vu.nl
} 
management has become an important and relevant discipline. A good planning of a project is important to reduce the project time. Two important methods to schedule and coordinate the activities in a project are the PERT (Program Evaluation Review Technique) and the CPM (Critical Path Method). During the last decades many studies have appeared addressing several issues as the question of assessing the project success in Pinto and Slevin (1988) and Tubig and Abeti (1990), the role of research in projects of weapon systems development in Sherwin and Isenson (1967), the problem of determining the amount, location, and timing of progress payments in projects from a client's perspective in Dayanand and Padman (2001), behavioral functions in technology-based innovative projects in Roberts and Fusfeld (1981), the classification of projects in types depending on the management style in Shenhar and Dvi (1996), the search of adequate success criteria for project management in Atkinson (1999) and the study of project scheduling with resource constrains in Dorndorf, Pesch and Phan-Huy (2000) and Möhring, Schulz, Stork and Uetz (2003).

An important problem within project management is the delay of a project. The delay in the construction of highways and railways connections brings both economical and social losses since society has to wait longer to enjoy their benefits. Delay is one of the most important issues for project managers. Quoting Mr. Rafael Romero, chairman of the Chamber of Constructors of Catalonia, "The expenditures used to prepare a project imply a saving of time and money" and "The suitability of a work goes through three fundamental pillars: security, finishing in the agreed deadline, and that the budget is met" (see http://www.lukor.com/notesp/locales/portada/08030207.htm). In many countries, when a public project is delayed, the government is legally entitled to fine the company in charge. Also in private projects there is usually a clause in the contract in which a penalty for the company is agreed upon if the project is finished later than planned. In all these cases, if the company in charge of the project has subcontracted some specialized jobs to other firms, and these firms have contributed to the delay, it is important to know for which part of the penalty they can be held responsible for. Opposite to extra costs associated to delay in projects, there may be extra rewards associated to expedited projects. As an example, we have the development of new high-technology devices. It is well known that development of high technology needs the input of different specialized agents. Besides, companies usually compete to be the first to have the new production on the market and therefore they promise a bonus to their employees if the product is finished before the agreed time. The subsequent question is how to share the bonus among the employees whose efforts resulted in the expedition of the project. The question we address in this paper is how to share the extra costs (or fine) among the agents responsible of the delay of a project, or the extra rewards in case of expedition.

Albeit delayed project problems and expedited project problems seem to be related, they have a different nature. While any firm or agent can delay a project on its own, a coordination of firms or agents is needed in order to expedite the project. In this paper we study both the allocation of extra costs and rewards simultaneously, taking into account the similarities and differences of both problems. Cooperative games 
are a mathematical tool to provide an answer to this type of allocation problems. The focus of our study will be on defining a game in an adequate way and analyzing the corresponding core. The core of a game (Gillies (1953)) provides allocations of the total penalty or the total reward that are stable, i.e. no group of activities can reasonably object to allocations in the core. The interaction between operations research and cooperative game theory already goes back to the seventies, for a survey on the topic see Borm, Hamers and Hendrickx (2001).

The main focus in the literature on project problems has been on delayed project problems. Branzêi, Ferrari, Fragnelli and Tijs (2002) study delayed project problems in the framework of taxation problems and propose a specific allocation rule. Bergantiños and Sánchez (2002) analyze two other allocation rules for delayed project problems. A common feature in these papers is however that game theoretical aspects are only indirectly present in analyzing the allocation problem at hand. Estévez-Fernández, Borm and Hamers (2007) is the first paper to approach the related allocation problem from a direct game theoretical point of view. Moreover, Estévez-Fernández et al. (2007) is the first article where both delayed and expedited project problems are analyzed. Still, the paper is restricted to project problems where the penalty (reward) function is proportional with respect to the total delay (expedition) of the project. An important aspect of Estévez-Fernández et al. (2007) is that it provides the tools to obtain "fair" allocations of the corresponding penalty or reward by explicitly considering the structure of the project, i.e. the interconnections among the different activities.

In this paper, we extend the work in Estévez-Fernández et al. (2007) by both analyzing project problems with arbitrary but nondecreasing penalty and reward functions and by taking into account whether an activity can be started before its planned starting time. As in Estévez-Fernández et al. (2007), the analysis is done by defining project games associated to project problems and considering the corresponding core as the solution set to the underlying allocation problem. We have decided to focus on the (set-valued solution) core instead of given an explicit one-point solution because this allows us to cover a wide variety of project situations that can have different needs depending, for instance, on the legal aspects that are applicable, which may vary depending on the type of project at hand and/or on the country where the project is realized. Here, two stages are needed to define project games for nondecreasing reward (penalty) functions. In the first stage surplus (cost) sharing problems are used. As a first approach to share the reward (penalty) of a project, we look at each path in the project separately and we share the reward (penalty) that the path can be held responsible of among its activities by making use of a surplus (cost) sharing mechanism which is chosen by taking into account the specific characteristics of the reward (penalty) function at hand. In this first stage, the total amount shared among all the activities may exceed the total reward (penalty) of the project, hence a second stage is needed to exactly obtain allocations of the total reward (penalty). In the second stage, a project game is defined in the spirit of Estévez-Fernández et al. (2007) using the allocations 
obtained in the first stage. Although the model here proposed is inspired in Estévez-Fernández et al. (2007), both games need not coincide when we restrict to proportional reward (penalty) functions. In fact, the core of the game defined here always contains the core of the game in Estévez-Fernández et al. (2007).

Our main result is that project games have a nonempty core. Moreover, it turns out that the games associated to the expedition part of the project are convex and can be described as the maximum of a number of bankruptcy games (see O'Neill (1982)).

The structure of this paper is as follows. Section 2 recalls some basic notions from project problems, cost and surplus sharing problems, cooperative games, and bankruptcy and taxation problems. Section 3 analyzes general project problems. Section 4 concludes.

\section{Preliminaries}

\section{$2.1 \quad$ Projects}

A project consists of a set of activities for which the inter-connections are known. These activities are completed over a period of time and intended to achieve a particular aim. Let $N$ denote the set of activities of a project. Given an activity $i \in N$, let $P_{i}$ denote the set of predecessors of $i$, i.e. the set of activities that have to be processed before $i$ can start. Analogously, let $F_{i}$ be the set of followers of $i$, i.e. the set of activities that need $i$ to be completed before starting. A project is defined as a collection of ordered subsets of $N$ or paths, $\left\{N_{1}, \ldots, N_{m}\right\}$, where a bijection $\sigma_{\alpha}:\left\{1, \ldots\left|N_{\alpha}\right|\right\} \rightarrow N_{\alpha}$ describes the order in $N_{\alpha}, \alpha \in\{1, \ldots, m\}$, satisfying the following conditions:

(i) $N=\bigcup_{\alpha=1}^{m} N_{\alpha}$;

(ii) $F_{\sigma_{\alpha}\left(\left|N_{\alpha}\right|\right)}=\emptyset, P_{\sigma_{\alpha}(1)}=\emptyset$, and $P_{\sigma_{\alpha}(r)}=\left\{\sigma_{\alpha}(1), \ldots, \sigma_{\alpha}(r-1)\right\}$ for every $\alpha \in\{1, \ldots, m\}$ and every $r \in\left\{2, \ldots,\left|N_{\alpha}\right|\right\}$

(iii) for $\alpha, \beta \in\{1, \ldots, m\}$, if $i, j \in N_{\alpha} \cap N_{\beta}$ with $\sigma_{\alpha}^{-1}(i)<\sigma_{\alpha}^{-1}(j)$, then $\sigma_{\beta}^{-1}(i)<\sigma_{\beta}^{-1}(j)$.

Throughout, there is no specific need to explicitly keep track of the ordering. Therefore, $\sigma_{1}, \ldots, \sigma_{m}$ are suppressed from the notations.

Note that a project can be represented by a directed graph where the set of arcs corresponds to the set of activities. In order to avoid multiple arcs, dummy activities are introduced in the graph (a dummy activity is a fictitious activity that does not consume neither time, nor resources). Dummy activities are represented by a dashed arc.

Example 2.1. Table 1 gives the set of activities of a project with their corresponding predecessors.

Here, the set of activities is $N=\{\mathrm{A}, \mathrm{B}, \mathrm{C}\}$ and the collection of paths is $\left\{N_{1}, N_{2}\right\}$, with $N_{1}=\{\mathrm{A}, \mathrm{C}\}$, and 


\begin{tabular}{|c|c|}
\hline Activity & Predecessors \\
\hline A & \\
\hline B & \\
\hline C & A,B \\
\hline
\end{tabular}

Table 1: Predecessors of activities in Example 2.1.

$N_{2}=\{\mathrm{B}, \mathrm{C}\}$. The graphical representation of this project is given in Figure 1.

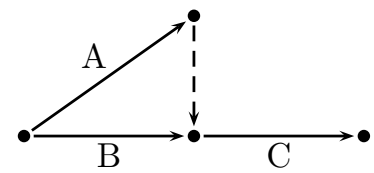

Figure 1: Representation of the project given in Table 1.

Associated to a project $\left\{N_{1}, \ldots, N_{m}\right\}$, there is a duration function $l: N \rightarrow \mathbb{R}_{+}$with $l(i)$ denoting the length or duration of activity $i \in N$. Given a project $\left\{N_{1}, \ldots, N_{m}\right\}$ and a duration function $l$, we define the duration of a path $N_{\alpha}$ according to $l, D\left(N_{\alpha}, l\right)$, as the sum of the duration of its activities, i.e. $D\left(N_{\alpha}, l\right)=\sum_{i \in N_{\alpha}} l(i)$. The duration of the project according to $l, D(l)$, is the maximum duration of its paths, i.e. $D(l)=\max _{1 \leq \alpha \leq m}\left\{D\left(N_{\alpha}, l\right)\right\}$. The slack of $N_{\alpha}$ according to $l$, slack $\left(N_{\alpha}, l\right)$, is the maximum time that the activities of $N_{\alpha}$ can be delayed without altering the duration of the project, i.e. $\operatorname{slack}\left(N_{\alpha}, l\right)=D(l)-D\left(N_{\alpha}, l\right)$. We say that a path is critical if it has slack zero. Associated to a project there is also an availability function $a: N \rightarrow \mathbb{R}_{+}$with $a(i)$ denoting the amount of time that activity $i$ can start before the planned time if necessary.

Example 2.2. Consider the project given in Example 2.1. Let $l: N \rightarrow \mathbb{R}_{+}$be given by $l(\mathrm{~A})=15, l(\mathrm{~B})=10$, and $l(\mathrm{C})=8$. Table 2 summarizes the duration and slack of the paths. Note that $D(l)=23$.

\begin{tabular}{|c|c|c|}
\hline$N_{\alpha}$ & $D\left(N_{\alpha}, l\right)$ & $\operatorname{slack}\left(N_{\alpha}, l\right)$ \\
\hline $\mathrm{AC}$ & 23 & 0 \\
\hline $\mathrm{BC}$ & 18 & 5 \\
\hline
\end{tabular}

Table 2: Duration and slack of the paths in Example 2.2.

Let $a: N \rightarrow \mathbb{R}_{+}$be given by $a(\mathrm{~A})=0, a(\mathrm{~B})=0$, and $a(\mathrm{C})=7$, then $\mathrm{A}$ and B cannot start before their planned starting time, while activity $\mathrm{C}$ could start 7 units of time before its planned starting time, i.e. C could start at time 8 . 
Throughout, we use a fixed notation for two specific duration functions. We denote by $p: N \rightarrow \mathbb{R}_{+}$the function representing the planned or estimated time of the activities and by $r: N \rightarrow \mathbb{R}_{+}$the function giving the real time of the activities after the realization of the project. We define the delay function $d: N \rightarrow \mathbb{R}_{+}$ as $d(i)=(r(i)-p(i))_{+}(:=\max \{r(i)-p(i), 0\})$, i.e. $d(i)$ represents the delay of activity $i$. Analogously, we define the expedition function $e: N \rightarrow \mathbb{R}_{+}$as $e(i)=(p(i)-r(i))_{+}$, i.e. $e(i)$ represents the expedition of activity $i$.

Example 2.3. Consider the project given in Example 2.1. Let the planned time $p: N \rightarrow \mathbb{R}_{+}$be given by $p(\mathrm{~A})=15, p(\mathrm{~B})=10$, and $p(\mathrm{C})=8$ and let the real time $r: N \rightarrow \mathbb{R}_{+}$be given by $r(\mathrm{~A})=7, r(\mathrm{~B})=6$, and $r(\mathrm{C})=12$. The delay and expedition functions are given in Table 3 .

\begin{tabular}{|c|c|c|c|}
\hline & $\mathrm{A}$ & $\mathrm{B}$ & $\mathrm{C}$ \\
\hline$d(i)$ & $(7-15)_{+}=0$ & $(6-10)_{+}=0$ & $(12-8)_{+}=4$ \\
\hline$e(i)$ & $(15-7)_{+}=8$ & $(10-6)_{+}=4$ & $(8-12)_{+}=0$ \\
\hline
\end{tabular}

Table 3: Delay and expedition functions in Example 2.3.

\subsection{Cost sharing and surplus sharing problems}

A cost sharing problem is defined by a tuple $(N, q, c)$ where $N=\{1,2, \ldots, n\}$ is the set of agents (or players), $q \in \mathbb{R}_{+}^{N}$ is a vector of nonnegative numbers, with $q_{i}$ representing the demand of agent $i \in N$, and $c: \mathbb{R} \rightarrow \mathbb{R}_{+}$ is a nondecreasing cost function satisfying $c(t)=0$ for $t \leq 0$. A cost sharing mechanism on a class of cost sharing problems $\mathcal{C}$ is a mapping $y$ that assigns to each $(N, q, c) \in \mathcal{C}$ a vector of cost shares $y(N, q, c) \in \mathbb{R}_{+}^{N}$, i.e. $\sum_{i \in N} y_{i}(N, q, c)=c\left(\sum_{i \in N} q_{i}\right)$, satisfying that if $q_{i}=0$, then $y_{i}(N, q, c)=0$.

Several mechanisms can be found in the literature (see e.g. Moulin (1987), Moulin and S. Shenker (1992), and Koster (1999)); we recall here one of the most studied cost sharing mechanisms in the literature, the serial cost sharing mechanism, $y^{s}$. Let $(N, q, c)$ be a cost sharing problem and assume without loss of generality that $q_{1} \leq q_{2} \leq \ldots \leq q_{n}$, then the proportional cost sharing mechanism is defined by

$$
\begin{aligned}
& y_{1}^{s}(N, q, c)=\frac{c\left(n q_{1}\right)}{n}, \\
& y_{i}^{s}(N, q, c)=\frac{c\left(n q_{1}\right)}{n}+\sum_{k=2}^{i} \frac{c\left(\sum_{j=1}^{k-1} q_{j}+(n-k+1) q_{k}\right)-c\left(\sum_{j=1}^{k-2} q_{j}+(n-k+2) q_{k-1}\right)}{n-k+1} \text { for every } i \in N \backslash\{1\} .
\end{aligned}
$$

Example 2.4. Let $(N, q, c)$ be a cost sharing problem with $N=\{1,2,3\}, q=(2,5,6)$, and $c$ defined by

$$
c(t)= \begin{cases}0 & \text { if } t \leq 0 \\ t^{2}+100 & \text { if } t>0\end{cases}
$$


In this case, $c(2+5+6)=269$ and $y^{s}(N, q, c)=\left(45 \frac{1}{3}, 99 \frac{1}{3}, 124 \frac{1}{3}\right)$. Table 4 summarizes the computation of the serial cost sharing rule.

\begin{tabular}{|l|c|}
\hline$t$ & $c(t)$ \\
\hline $3 q_{1}=6$ & 136 \\
\hline$q_{1}+2 q_{2}=12$ & 244 \\
\hline$q_{1}+q_{2}+q_{3}=13$ & 269 \\
\hline
\end{tabular}

\begin{tabular}{|c|c|c|c|c|}
\hline$i$ & $\frac{c(6)}{3}$ & $\frac{c(12)-c(6)}{2}$ & $\frac{c(13)-c(12)}{1}$ & $y^{s}$ \\
\hline 1 & $\frac{136}{3}=45 \frac{1}{3}$ & & & $45 \frac{1}{3}$ \\
\hline 2 & $\frac{136}{3}=45 \frac{1}{3}$ & $\frac{108}{2}=54$ & & $99 \frac{1}{3}$ \\
\hline 3 & $\frac{136}{3}=45 \frac{1}{3}$ & $\frac{108}{2}=54$ & $\frac{25}{1}=25$ & $124 \frac{1}{3}$ \\
\hline
\end{tabular}

Table 4: Computation of the cost sharing rule in Example 2.4.

Analogously to cost sharing problems, one can think of surplus sharing problems. All definitions given above for cost sharing problems can be easily translated to surplus sharing problems.

\subsection{Transferable utility (TU) games}

A cooperative (TU) game in characteristic function form is an ordered pair $(N, v)$ where $N$ is a finite set of players and $v: 2^{N} \rightarrow \mathbb{R}$ satisfying $v(\emptyset)=0$. In general, $v(S)$ represents the value of coalition $S$, i.e. the joint payoff that can be obtained by this coalition when its members decide to cooperate.

A cooperative game can reflect costs or rewards. A game reflecting costs is denoted by a mapping $c$, while a game reflecting rewards is denoted by a mapping $v$.

The core of a game $(N, v)$ is defined by

$$
\operatorname{Core}(v)=\left\{x \in \mathbb{R}^{N} \mid \sum_{i \in N} x_{i}=v(N), \sum_{i \in S} x_{i} \geq v(S) \text { for all } S \in 2^{N}\right\},
$$

i.e. the core is the set of efficient allocations of $v(N)$ to which no coalition can reasonably object. An important subclass of games with nonempty core is the class of convex games (see Shapley (1971)). A game $(N, v)$ is said to be convex if $v(S \cup\{i\})-v(S) \leq v(T \cup\{i\})-v(T)$ for every $i \in N$ and every $S \subset T \subset N \backslash\{i\}$.

Let $(N, c)$ be a cost game. The corresponding cost savings game $(N, v)$ is defined by

$$
v(S)=\sum_{i \in S} c(\{i\})-c(S)
$$

for all $S \subset N$.

The properties and solution concepts for cooperative cost games can consequently be derived from the above definitions. The equivalent of a convex game for a cost game is a concave game.

\subsection{Bankruptcy and taxation problems}

A bankruptcy problem is defined by a tuple $(N, E, c)$ where $N=\{1, \ldots, n\}$ is the set of agents (or players), $E$ is the estate that must be shared among the agents, and $c \in \mathbb{R}^{N}$ is the vector of claims of the agents 
satisfying $\sum_{i \in N} c_{i}>E$. Bankruptcy problems have being firstly studied from a game theoretical viewpoint in O'Neill (1982). Given a bankruptcy problem $(N, E, c)$, the corresponding bankruptcy game, $\left(N, v_{(N, E, c)}\right)$, is defined by

$$
v_{(N, E, c)}(S)=\left(E-\sum_{i \in N \backslash S} c_{i}\right)_{+}
$$

for every $S \subset N$. In Curiel et al. (1987) it is shown that bankruptcy games are convex.

Taxation problems can be seen as dual of bankruptcy problems. A taxation problem is defined by a tuple $(N, E, c)$ where $N=\{1, \ldots, n\}$ is the set of agents (or players), $E$ is the tax that must be collected among the agents, and $c \in \mathbb{R}^{N}$ is the vector of the abilities to pay of the players satisfying $\sum_{i \in N} c_{i}>E$. Given a taxation problem $(N, E, c)$, the corresponding taxation game, $\left(N, c_{(N, E, c)}\right)$, is defined by

$$
c_{(N, E, c)}(S)=\min \left\{E, \sum_{i \in S} c_{i}\right\}
$$

for every $S \subset N$. In Branzêi et al. (2002) it is shown that taxation games are concave.

\section{Project problems}

A project problem arises when the planned time of the activities has been incorrectly estimated, possibly bringing delay or expedition and associated extra costs or rewards to the project. We study project problems in terms of rewards, where a negative reward reflects costs. A nondecreasing reward function $R: \mathbb{R} \rightarrow \mathbb{R}$ is associated to the difference between the planned and real times of the project, satisfying $R(t) \leq 0$ for $t<0, R(t)=0$ for $t=0$, and $R(t) \geq 0$ for $t>0$. A project problem can be described by a 5 -tuple $\left(\left\{N_{1}, \ldots, N_{m}\right\}, p, r, a, R\right)$ where $p$ and $r$ satisfy $p \neq r$. For simplicity of notation, we omit the vector of availabilities $a$ from the description of a project problem whenever all activities can be started as soon as needed.

When a reward forms due to the difference between the planned and real times of a project, one can think of sharing the delay or expedition of the project among the activities in a first (linear) stage and allocating the (possibly nonlinear) reward among the activities according to the delay or expedition they have been held responsible of in a second stage. This approach has already been suggested in Branzêi et al. (2002). The problem with this procedure is that the specific characteristics of the reward function may be neglected. We show the inadequacy of this procedure in the following example in which the allocation of the total difference in time is obtained by considering the core of the game defined in Estévez-Fernández et al. (2007).

Example 3.1. Consider the project problem $\left(\left\{N_{1}, N_{2}, N_{3}, N_{4}\right\}, p, r, R\right)$ with $N_{1}=\{\mathrm{A}\}, N_{2}=\{\mathrm{B}\}, N_{3}=$ $\{\mathrm{C}, \mathrm{D}\}, N_{4}=\{\mathrm{E}\} ; p(\mathrm{~A})=21, p(\mathrm{~B})=19, p(\mathrm{C})=2, p(\mathrm{D})=16, p(\mathrm{E})=17 ; r(\mathrm{~A})=14, r(\mathrm{~B})=15, r(\mathrm{C})=7$, 
$r(\mathrm{D})=6, r(\mathrm{E})=14 ;$ and $R(t)= \begin{cases}-20 t^{2} & \text { if } t \leq 0, \\ t^{4} & \text { if } 0<t \leq 4, \\ t^{2}+240 & \text { if } t>4 .\end{cases}$

Note that $d(\mathrm{~A})=0, d(\mathrm{~B})=0, d(\mathrm{C})=5, d(\mathrm{D})=0, d(\mathrm{E})=0, e(\mathrm{~A})=7, e(\mathrm{~B})=4, e(\mathrm{C})=0, e(\mathrm{D})=10$ and $e(\mathrm{E})=3$. The project is represented in Figure 2 .

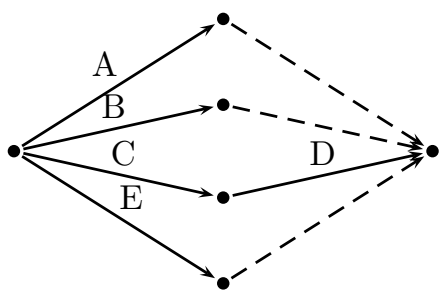

\begin{tabular}{|c|c|c|c|}
\hline$N_{\alpha}$ & $D\left(N_{\alpha}, p\right)$ & $\operatorname{slack}\left(N_{\alpha}, p\right)$ & $D\left(N_{\alpha}, r\right)$ \\
\hline $\mathrm{A}$ & 21 & 0 & 14 \\
\hline $\mathrm{B}$ & 19 & 2 & 15 \\
\hline $\mathrm{CD}$ & 18 & 3 & 13 \\
\hline $\mathrm{E}$ & 17 & 4 & 14 \\
\hline
\end{tabular}

Figure 2: Representation of the project given in Example 3.1 and duration of the paths.

Here, $D(p)=21$ and $D(r)=15$, and then the total expedition is $D(p)-D(r)=6$ with an associated reward of $R(6)=276$.

Following the suggested two-stage approach, we first share the total expedition of 6 among the activities by making use of the associated linear project game given in Estévez-Fernández et al. (2007). All coalitional values are given in Table 5.

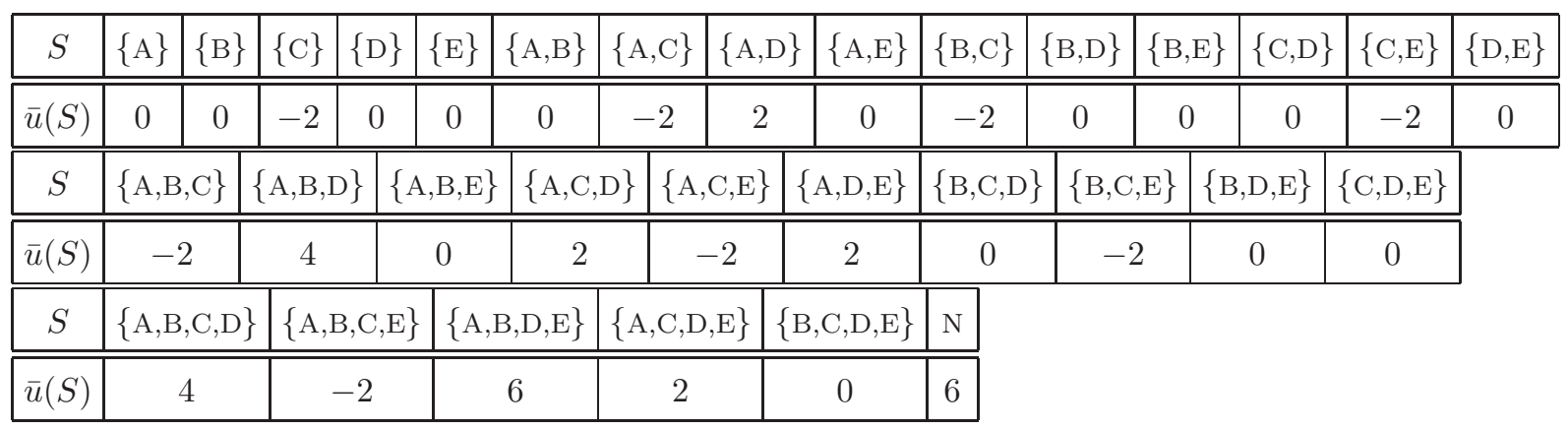

Table 5: Coalitional values in Example 3.1.

It can be easily checked that $(2,2,-2,2,2) \in \operatorname{Core}(\bar{u})$. Fix $(2,2,-2,2,2)$ as the allocation of the total expedition among the activities. Here, we encounter two problems. The first problem is of an interpretational nature. Activity $\mathrm{C}$ is held responsible of 2 units of delay, but it is not clear what is the monetary equivalence of this delay. Is it given by the penalty part or by the bonus part of the reward function? The second problem is the loss of the characteristics of the reward function when applying proportionality. By dividing the total reward proportionally to the allocation of responsibilities $(2,2,-2,2,2)$, as suggested in Branzêi et al. (2002), an allocation of $(92,92,-92,92,92)$ is obtained. Note that without the expedition of activity D, activity C would have created a delay of 2 with a reward of $R(-2)=-80$. However, the allocation assigns a total penalty of 92 to $\mathrm{C}$. 
As pointed out in the example above, the inadequacy in first sharing "responsibilities" among the activities and then the reward in a second stage is that the characteristics of the reward function are not reflected on the final share of the total reward. Our approach follows the opposite reasoning. We first allocate the reward associated to the delay or expedition of each path (i.e. the total delay or total expedition created by its activities) among its activities. In a second step, we use cooperative games to share the reward of the project among all its activities, using the initial allocations as reference points.

Associated to a project problem $\left(\left\{N_{1}, \ldots, N_{m}\right\}, p, r, a, R\right)$, we define a project game where the set of players is the set of activities and the value of a coalition is determined by taking into account the similarities and differences of both delayed and expedited projects. In determining the value of a coalition we pessimistically assume that all delayed activities have indeed acted according to realization and that all expedited activities outside the coalition have acted according to plan. Then, if the expedition given by the expedited activities in the coalition itself is not enough to expedite the duration of the project, the value of the coalition is negative and is determined through a cost game. Otherwise, the value of the coalition is positive and is determined through a reward game. Formally, given a project problem $\left(\left\{N_{1}, \ldots, N_{m}\right\}, p, r, a, R\right)$, a cost sharing mechanism $y$, and a surplus sharing mechanism $z$, we denote by $\left(N, u_{y z}\right)$ the associated project game, still to be formally defined. Let $\mathcal{E}$ denote the set of expedited activities, i.e. $\mathcal{E}=\{i \in N \mid e(i)>0\}$.

\subsection{Delay in project problems}

If $D\left(p_{\mid \mathcal{E} \backslash S}, r_{\mid N \backslash(\mathcal{E} \backslash S)}\right) \geq D(p)$, then the expedition carried by the expedited activities in $S$ is not enough to expedite the project and $c_{y}(S)$ reflects the maximum delay that the coalition can be held responsible of.

If activities in a path are delayed and they cause a delay of the project, we can consider this as a cost sharing problem where the demands of the activities are their delays and the cost function is the negative part of the reward function. For every $\alpha \in\{1, \ldots, m\}$, consider the cost sharing problem

$$
\left(N_{\alpha}, q^{\alpha}, K\right)
$$

with $q_{i}^{\alpha}=d(i)$ for every $i \in N_{\alpha}$ and $K(t)=-R(-t)$ if $t>0$ and $K(t)=0$ otherwise. Selecting a cost sharing mechanism $y$ by taking into account the type of penalty function at hand, we define $y^{\alpha}=y\left(N_{\alpha}, q^{\alpha}, K\right)$. Here, we pessimistically assume that the activities in $N_{\alpha}$ are not allowed to make use neither of the planned slack, nor of the expedition created by other activities in the path and have to pay the cost associated to their total delay. In this way, $y_{i}^{\alpha}$ represents the cost that $i$ is held responsible of for the cost associated to the total delay of the activities in $N_{\alpha}$. By using these allocations as starting points, the activities of coalition $S$ that are in path $\alpha$ cannot be held responsible neither for more than the total cost assigned to them by the cost sharing mechanism, nor for more than the net delay of the path as a consequence of the delay of activities in the path and the expedition of the activities within the coalition. The value of coalition $S$ is 
then the maximal amount that the coalition can be held responsible of with respect to the different paths involved in the coalition. Formally,

$$
c_{y}(S)=\max _{\alpha \in \mathcal{P}(S)}\left\{\min \left\{\sum_{i \in N_{\alpha} \cap S} y_{i}^{\alpha}, K\left(D\left(N_{\alpha},\left(p_{\mid \varepsilon \backslash S}, r_{\mid N \backslash(\varepsilon \backslash S)}\right)\right)-D(p)\right)\right\}\right\},
$$

where $\mathcal{P}(S)$ represents the set of paths in which $S$ is involved, i.e. $\mathcal{P}(S)=\left\{\alpha \in\{1, \ldots, m\} \mid N_{\alpha} \cap S \neq \emptyset\right\}$. Note that $c_{y}(N)=K(D(r)-D(p))$ since $\min \left\{\sum_{i \in N_{\alpha}} y_{i}^{\alpha}, K\left(D\left(N_{\alpha}, r\right)-D(p)\right)\right\}=K\left(D\left(N_{\alpha}, r\right)-D(p)\right)$ for every $\alpha \in\{1, \ldots, m\}$.

Example 3.2. Consider the project problem $\left(\left\{N_{1}, N_{2}, N_{3}\right\}, p, r, R\right)$ with $N_{1}=\{\mathrm{A}, \mathrm{B}\}, N_{2}=\{\mathrm{A}, \mathrm{D}\}$, $N_{3}=\{\mathrm{C}, \mathrm{D}\} ; p(\mathrm{~A})=2, p(\mathrm{~B})=15, p(\mathrm{C})=13, p(\mathrm{D})=3 ; r(\mathrm{~A})=9, r(\mathrm{~B})=11, r(\mathrm{C})=12, r(\mathrm{D})=8$; and $R(t)=\left\{\begin{array}{ll}-t^{4}-100 & \text { if } t<0, \\ 0 & \text { if } t=0, \\ t^{2}+200 & \text { if } t>0 .\end{array}\right.$ The project is represented in Figure 3.

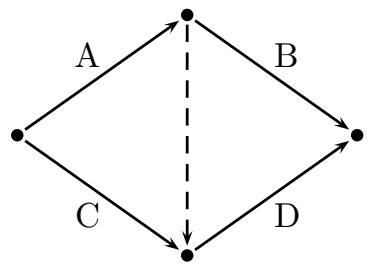

\begin{tabular}{|c|c|c|c|}
\hline$N_{\alpha}$ & $D\left(N_{\alpha}, p\right)$ & $\operatorname{slack}\left(N_{\alpha}, p\right)$ & $D\left(N_{\alpha}, r\right)$ \\
\hline $\mathrm{AB}$ & 17 & 0 & 20 \\
\hline $\mathrm{AD}$ & 5 & 12 & 17 \\
\hline $\mathrm{CD}$ & 16 & 1 & 20 \\
\hline
\end{tabular}

Figure 3: Representation of the project given in Example 3.2 and duration of the paths.

Here, $D(p)=17$ and $D(r)=20$, and then the difference of time is $D(p)-D(r)=-3$ with an associated reward of $R(-3)=-181$. Besides, $d(\mathrm{~A})=7, d(\mathrm{~B})=0, d(\mathrm{C})=0$ and $d(\mathrm{D})=5 ; e(\mathrm{~A})=0, e(\mathrm{~B})=4, e(\mathrm{C})=1$ and $e(\mathrm{D})=0$; and $\mathcal{E}=\{\mathrm{B}, \mathrm{C}\}$.

For the computation of $\left(N, c_{y}\right)$ we use the serial cost sharing mechanism. Associated to each path $N_{\alpha}$ we have the cost sharing problem $\left(N_{\alpha}, q^{\alpha}, K\right)$, with $q_{i}^{\alpha}=d(i)$ and $K(t)=0$ if $t \leq 0$ and $K(t)=t^{4}+100$ if $t>0$. Then, $y^{1}=y(\{\mathrm{~A}, \mathrm{~B}\},(7,0), K)=(2501,0), y^{2}=y(\{\mathrm{~A}, \mathrm{D}\},(7,5), K)=(15786,5050)$, and $y^{3}=$ $y(\{\mathrm{C}, \mathrm{D}\},(0,5), K)=(0,725)$. Below, the computation of $c_{y}(\{\mathrm{~A}, \mathrm{~B}, \mathrm{C}\})$ is explained.

$$
\begin{aligned}
c_{y}(\{\mathrm{~A}, \mathrm{~B}, \mathrm{C}\}) & =\max _{\alpha \in \mathcal{P}(\{\mathrm{A}, \mathrm{B}, \mathrm{C}\})}\left\{\min \left\{\sum_{i \in N_{\alpha} \cap S} y_{i}^{\alpha}, K\left(D\left(N_{\alpha},\left(p_{\mid \varepsilon \backslash S}, r_{\mid N \backslash(\varepsilon \backslash S)}\right)\right)-D(p)\right)\right\}\right\} \\
& =\max _{\alpha \in\{1,2,3\}}\left\{\min \left\{\sum_{i \in N_{\alpha} \cap S} y_{i}^{\alpha}, K\left(D\left(N_{\alpha},\left(p_{\mid \varepsilon \backslash S}, r_{\mid N \backslash(\mathcal{E} \backslash S)}\right)\right)-D(p)\right)\right\}\right\} \\
& =\max \{\min \{2501+0, K(20-17)\}, \min \{15786, K(17-17)\}, \\
& \quad \min \{0, K(20-17)\}\} \\
& =\max \{\min \{2501,181\}, \min \{15786,0\}, \min \{0,181\}\} \\
& =\max \{181,0,0\}
\end{aligned}
$$




$$
=181 .
$$

All coalitional values are given in Table 6 .

\begin{tabular}{|c|c|c|c|c|c|c|c|c|c|c|c|c|c|c|c|}
\hline$S$ & $\{\mathrm{~A}\}$ & $\{\mathrm{B}\}$ & $\{\mathrm{C}\}$ & $\{\mathrm{D}\}$ & $\{\mathrm{A}, \mathrm{B}\}$ & $\{\mathrm{A}, \mathrm{C}\}$ & $\{\mathrm{A}, \mathrm{D}\}$ & $\{\mathrm{B}, \mathrm{C}\}$ & $\{\mathrm{B}, \mathrm{D}\}$ & $\{\mathrm{C}, \mathrm{D}\}$ & $\{\mathrm{A}, \mathrm{B}, \mathrm{C}\}$ & $\{\mathrm{A}, \mathrm{B}, \mathrm{D}\}$ & $\{\mathrm{A}, \mathrm{C}, \mathrm{D}\}$ & $\{\mathrm{B}, \mathrm{C}, \mathrm{D}\}$ & $\mathrm{N}$ \\
\hline \hline$c_{y}(S)$ & 2501 & 0 & 0 & 356 & 181 & 2501 & 2501 & 0 & 356 & 181 & 181 & 356 & 2501 & 181 & 181 \\
\hline
\end{tabular}

Table 6: Coalitional values in Example 3.2.

It can be checked that the core of the game is

$$
\begin{gathered}
\operatorname{Core}\left(c_{y}\right)=\operatorname{conv}\{(0,0,-175,356),(0,0,0,181),(2320,-2320,0,181),(2501,-2320,0,0), \\
(2145,-2145,-175,356),(181,0,-175,175),(181,0,0,0)\} .
\end{gathered}
$$

Note that this game is not concave by taking $i=\mathrm{B}, S=\{\mathrm{A}\}$, and $T=\{\mathrm{A}, \mathrm{D}\}$ since $c_{y}(\{\mathrm{~A}, \mathrm{~B}\})-c_{y}(\{\mathrm{~A}\})=$ $-2320 \nsupseteq-2145=c_{y}(\{\mathrm{~A}, \mathrm{~B}, \mathrm{D}\})-c_{y}(\{\mathrm{~A}, \mathrm{D}\})$.

Theorem 3.1. Let $\left(\left\{N_{1}, \ldots, N_{m}\right\}, p, r, a, R\right)$ be a project problem and let $y$ be a cost sharing mechanism. Then, $\left(N, c_{y}\right)$ has a nonempty core.

Proof: Let $\hat{\alpha} \in\{1, \ldots, m\}$ be such that $D(r)=D\left(N_{\hat{\alpha}}, r\right)$, i.e. $N_{\hat{\alpha}}$ is responsible of the total delay of the project. Consider the taxation problem $\left(N, E^{\hat{\alpha}}, c^{\hat{\alpha}}\right)$ given by $E^{\hat{\alpha}}=K\left(D\left(N_{\hat{\alpha}}, r\right)-D(p)\right), c_{i}^{\hat{\alpha}}=y_{i}^{\hat{\alpha}}$ if $i \in N_{\hat{\alpha}}$ and $c_{i}^{\hat{\alpha}}=0$ if $i \in N \backslash N_{\hat{\alpha}}$. Then,

$$
\begin{aligned}
c_{y}(N) & =K\left(D\left(N_{\hat{\alpha}}, r\right)-D(p)\right) \\
& =\min \left\{\sum_{i \in N_{\hat{\alpha}}} y_{i}^{\hat{\alpha}}, K\left(D\left(N_{\hat{\alpha}}, r\right)-D(p)\right)\right\} \\
& =\min \left\{\sum_{i \in N} c_{i}^{\hat{\alpha}}, E^{\hat{\alpha}}\right\} \\
& =c_{\left(N, E^{\hat{\alpha}}, c^{\hat{\alpha}}\right)}(N)
\end{aligned}
$$

where the first equality follows because $D(r)=D\left(N_{\hat{\alpha}}, r\right)$, the second one is a direct consequence of $K\left(D\left(N_{\hat{\alpha}}, r\right)-D(p)\right) \leq K\left(\sum_{i \in N_{\hat{\alpha}}} d(i)\right)=\sum_{i \in N_{\hat{\alpha}}} y_{i}^{\hat{\alpha}}$ since $R$ is nondecreasing and hence $K$ is also nondecreasing, and the third one is a direct consequence of the definition of $E^{\hat{\alpha}}$ and $c^{\hat{\alpha}}$. Moreover, for every $S \subset N$ we have

$$
\begin{aligned}
c_{y}(S) & =\max _{\alpha \in \mathcal{P}(S)}\left\{\min \left\{\sum_{i \in N_{\alpha} \cap S} y_{i}^{\alpha}, K\left(D\left(N_{\alpha},\left(p_{\mid \mathcal{E} \backslash S}, r_{\mid N \backslash(\mathcal{E} \backslash S)}\right)\right)-D(p)\right)\right\}\right\} \\
& \geq \min \left\{\sum_{i \in N_{\hat{\alpha}} \cap S} y_{i}^{\hat{\alpha}}, K\left(D\left(N_{\hat{\alpha}},\left(p_{\mid \mathcal{E} \backslash S}, r_{\mid N \backslash(\mathcal{E} \backslash S)}\right)\right)-D(p)\right)\right\}
\end{aligned}
$$




$$
\begin{aligned}
& \geq \min \left\{\sum_{i \in N_{\hat{\alpha}} \cap S} y_{i}^{\hat{\alpha}}, K\left(D\left(N_{\hat{\alpha}}, r\right)-D(p)\right)\right\} \\
& =\min \left\{\sum_{i \in S} c_{i}^{\hat{\alpha}}, E^{\hat{\alpha}}\right\} \\
& =c_{\left(N, E^{\hat{\alpha}}, c^{\hat{\alpha}}\right)}(S)
\end{aligned}
$$

where the second inequality follows because $R$ is nondecreasing and therefore $K$ is also nondecreasing, and the second equality is a direct consequence of the definitions of $E^{\hat{\alpha}}$ and $c^{\hat{\alpha}}$.

Since $\left(N_{\hat{\alpha}}, c_{\left(N, E^{\hat{\alpha}}, c^{\hat{\alpha}}\right)}\right)$ is concave, we know that there is an $x \in \operatorname{Core}\left(c_{\left(N, E^{\hat{\alpha}}, c^{\hat{\alpha}}\right)}\right)$ and then $\sum_{i \in N} x_{i}=$ $c_{\left(N, E^{\hat{\alpha}}, c^{\hat{\alpha}}\right)}(N)=c_{y}(N)$ and $\sum_{i \in S} x_{i} \leq c_{\left(N, E^{\hat{\alpha}}, c^{\hat{\alpha}}\right)}(S) \leq c_{y}(S)$ for every $S \subset N$, and therefore $x \in \operatorname{Core}\left(c_{y}\right)$.

\subsection{Expedition in project problems}

If $D\left(p_{\mid \mathcal{E} \backslash S}, r_{\mid N \backslash(\mathcal{E} \backslash S)}\right)<D(p)$, then the expedition created by the expedited activities in $S$ is enough to expedite the project and $v_{z}(S)$ reflects the amount of reward from the expedition that the coalition may claim.

Before starting with the description of the expedited part of project games, we give the following example that illustrates the ideas behind the model.

Example 3.3. Consider the project problem $\left(\left\{N_{1}, N_{2}, N_{3}, N_{4}\right\}, p, r, R\right)$ in Example 3.1. Recall that $N_{1}=$ $\{\mathrm{A}\}, N_{2}=\{\mathrm{B}\}, N_{3}=\{\mathrm{C}, \mathrm{D}\}$ and $N_{4}=\{\mathrm{E}\} ; p(\mathrm{~A})=21, p(\mathrm{~B})=19, p(\mathrm{C})=2, p(\mathrm{D})=16$ and $p(\mathrm{E})=17 ;$ $r(\mathrm{~A})=14, r(\mathrm{~B})=15, r(\mathrm{C})=7, r(\mathrm{D})=6$ and $r(\mathrm{E})=14 ;$ and $R(t)=\left\{\begin{array}{ll}-20 t^{2} & \text { if } t \leq 0, \\ t^{4} & \text { if } 0<t \leq 4, \\ t^{2}+240 & \text { if } t>4 .\end{array}\right.$ The project is represented in Figure 2.

In this project problem, $D(p)=21$ and $D(r)=15$, therefore there is a total expedition of $D(p)-D(r)=6$ and a reward of $R(6)=276$.

Note that the critical path $N_{1}=\{\mathrm{A}\}$ is always indispensable to expedite the project. Moreover, due to the delay of activity $\mathrm{C}$, activity $\mathrm{D}$ is also indispensable to expedite the project. We subsequently explain how this expedition is achieved. First, suppose that the delayed activities (activity $C$ ) act according to realization while the expedited activities act according to plan. Second, assume that both the expedited activities in $N_{3}$, i.e. activity D, and the activities in $N_{1}$ act according to realization while activities in $N_{2}$ and $N_{4}$ act according to plan, then the project is expedited in 2 with an associated reward of $R(2)=16$, and $N_{2}$ becomes critical. Note that $N_{1}$ and $N_{3}$ are exclusively responsible of a reward of 16 , and that $N_{2}$ becomes indispensable to continue expediting. Third, suppose that also activities in $N_{2}$ act according to realization, then the project 
has an extra expedition of 2 with an associated marginal reward of $R(4)-R(2)=256-16=240$ of which $N_{1}$, $N_{2}$, and $N_{3}$ are responsible. Last, suppose that all activities act according to realization, then the project has an extra expedition of 2 with an associated marginal reward of $R(6)-R(4)=276-256=20$ of which $N_{1}$, $N_{2}, N_{3}$ and $N_{4}$ are responsible. The description of the sequence in which realization times are considered for the activities is given in Table 7.a and the contribution of the paths to the reward obtained by the expedition of the project is summarized in Table 7.b.

\begin{tabular}{|c|c|c|c|c|c|}
\hline & $\begin{array}{c}p_{\mathrm{A}}=21 \\
p_{\mathrm{B}}=19 \\
p_{\mathrm{C}}=2, p_{\mathrm{D}}=16 \\
p_{\mathrm{E}}=17\end{array}$ & $\begin{array}{c}p_{\mathrm{A}}=21 \\
p_{\mathrm{B}}=19 \\
r_{\mathrm{C}}=7, p_{\mathrm{D}}=16 \\
p_{\mathrm{E}}=17\end{array}$ & $\begin{array}{c}r_{\mathrm{A}}=14 \\
p_{\mathrm{B}}=19 \\
r_{\mathrm{C}}=7, r_{\mathrm{D}}=6 \\
p_{\mathrm{E}}=17\end{array}$ & $\begin{array}{c}r_{\mathrm{A}}=14 \\
r_{\mathrm{B}}=15 \\
r_{\mathrm{C}}=7, r_{\mathrm{D}}=6 \\
p_{\mathrm{E}}=17\end{array}$ & $\begin{array}{c}r_{\mathrm{A}}=14 \\
r_{\mathrm{B}}=15 \\
r_{\mathrm{C}}=7, r_{\mathrm{D}}=6 \\
r_{\mathrm{E}}=14\end{array}$ \\
\hline$N_{1}$ & $\mathbf{2 1}$ & 21 & 14 & 14 & 14 \\
\hline$N_{2}$ & 19 & 19 & $\mathbf{1 9}$ & 15 & $\mathbf{1 5}$ \\
\hline$N_{3}$ & 18 & $\mathbf{2 3}$ & 13 & 13 & 13 \\
\hline$N_{4}$ & 17 & 17 & 17 & $\mathbf{1 7}$ & 14 \\
\hline
\end{tabular}

a: Description of the sequence in which realization times are considered for the activities.

\begin{tabular}{|c|c|c|c|}
\hline & Phase 1 & Phase 2 & Phase 3 \\
\hline$N_{1}$ & 16 & 240 & 20 \\
\hline$N_{2}$ & 0 & 240 & 20 \\
\hline$N_{3}$ & 16 & 240 & 20 \\
\hline$N_{4}$ & 0 & 0 & 20 \\
\hline
\end{tabular}
reward by means of levels of expedition.

Table 7: Description of the decomposition of the total rewards by levels of expedition in Example 3.3.

Note that the sum of both the first and third rows in Table 7.b gives the total reward. This type of decomposition by means of levels of expedition plays an important role in the definition of the expedited part of project games.

In order to define the value corresponding to the expedited part of a project game, we first optimistically allocate the part of the expedition that each path could contribute to among its activities. In a second step, we define the value of the game using the initial allocations as reference points.

Before defining $v_{z}$, we need to introduce some notation. We denote by $\operatorname{rslack}\left(N_{\alpha}, p, r\right)$ the amount of remaining slack of a path with respect to the planned duration if only its delayed activities act according to realization, i.e. $\operatorname{rslack}\left(N_{\alpha}, p, r\right)=\operatorname{slack}\left(N_{\alpha}, p\right)-\sum_{i \in N_{\alpha}} d(i)$. Note that $\operatorname{rslack}\left(N_{\alpha}, p, r\right)$ can be negative, meaning that the delayed activities have consumed all the initial slack and would produce a delay on the project, as a whole, of $-\operatorname{rslack}\left(N_{\alpha}, p, r\right)$ if the expedited activities had acted according to plan. We denote by $J_{1}$ the set (of indexes) of paths with remaining slack less than or equal to zero:

$$
J_{1}=\left\{\alpha \in\{1, \ldots, m\} \mid \operatorname{rslack}\left(N_{\alpha}, p, r\right) \leq 0\right\}
$$

Recursively, we define for $k \geq 2$

$$
J_{k}=\left\{\alpha \in\{1, \ldots, m\} \backslash \bigcup_{l=1}^{k-1} J_{l} \mid \operatorname{rslack}\left(N_{\alpha}, p, r\right) \leq \operatorname{rslack}\left(N_{\beta}, p, r\right) \text { for all } \beta \in\{1, \ldots, m\} \backslash \bigcup \bigcup_{l=1}^{k-1} J_{l}\right\}
$$


i.e. $J_{k}$ contains all paths that would have smallest remaining slack if the paths in $J_{1}, \ldots, J_{k-1}$ where not present. Set $\operatorname{rslack}\left(J_{1}\right):=0$ and let $\operatorname{rslack}\left(J_{k}\right)$ denote the remaining slack of the paths in $J_{k}$ for $k \geq 2$, i.e. $\operatorname{rslack}\left(J_{k}\right)=\operatorname{rslack}\left(N_{\alpha}, p, r\right)$ for each $\alpha \in J_{k}, k \geq 2$. Let $g$ be such that $\operatorname{rslack}\left(J_{g}\right)<D(p)-D(r) \leq$ $\operatorname{rslack}\left(J_{g+1}\right)$ if $D(p)-D(r)>0$ and $g=0$ otherwise. For $k=1, \ldots, g$, we define $F^{k}$ as the marginal contribution of the paths in $J_{1}, \ldots, J_{k}$ to the total reward associated to the expedition. Formally,

$$
F^{k}= \begin{cases}R\left(\operatorname{rslack}\left(J_{k+1}\right)\right)-R\left(\operatorname{rslack}\left(J_{k}\right)\right) & \text { if } 1 \leq k<g \\ R(D(p)-D(r))-R\left(\operatorname{rslack}\left(J_{g}\right)\right) & \text { if } k=g .\end{cases}
$$

Note that $\sum_{k=1}^{g} F^{k}=R(D(p)-D(r))$ since $R\left(\operatorname{rslack}\left(J_{1}\right)\right)=0$.

For every $\alpha \in\{1, \ldots, m\}$, consider the surplus sharing problem

$$
\left(N_{\alpha}, p^{\alpha}, R^{\alpha}\right)
$$

with $^{1} p_{i}^{\alpha}=\min \left\{e(i), \min _{j \in N_{\alpha} \cap F_{i}}\{a(j)\}\right\}$ for every $i \in N_{\alpha}$ (i.e. since activity $i$ needs to coordinate with its followers to expedite the project, $i$ cannot expedite the path $e(i)$ if its followers do not have enough availability to start as soon as allowed by $i$ 's expedition) and $R^{\alpha}(t)=R\left(t+\left(\operatorname{rslack}\left(N_{\alpha}, p\right)\right)_{+}\right)-R\left(\left(\operatorname{rslack}\left(N_{\alpha}, p\right)\right)_{+}\right)$if $t \geq 0$ and $R^{\alpha}(t)=0$ otherwise.

Selecting a surplus sharing mechanism $z$ (taking into account the type of reward function at hand), we denote by $z^{\alpha}$ the allocation proposed by our mechanism to the surplus sharing problem $\left(N_{\alpha}, p^{\alpha}, R^{\alpha}\right)$, i.e. $z^{\alpha}=z\left(N_{\alpha}, p^{\alpha}, R^{\alpha}\right)$. Here, $z_{i}^{\alpha}$ is the maximum amount that $i$ can claim according to the surplus sharing mechanism if its path is awarded with the total expedition that it can bring to the project. Then, we optimistically define the vector of maximal rewards, $f^{z}$, by

$$
f_{i}^{z}=\max _{\alpha: N_{\alpha} \ni i}\left\{z_{i}^{\alpha}\right\}
$$

i.e. $f_{i}^{z}$ is the maximum reward that activity $i$ can claim from the expedition of the project when the surplus sharing mechanism $z$ is considered.

Next, we define $v_{z}(S)$ representing the sum over all $k \in\{1, \ldots, g\}$ of those specific parts of the contribution to the total reward $F^{k}$ for which the activities outside the coalition that are in paths of $\bigcup_{l=1}^{k} J_{l}$ cannot be held responsible for anymore at that phase. Formally ${ }^{2}$,

$$
v_{z}(S)=\sum_{k=1}^{g}\left(F^{k}-w_{z}^{k}(S)\right)
$$

\footnotetext{
${ }^{1}$ Note that if all followers of $i$ in path $\alpha$ have enough availability to start as soon as needed, then $p_{i}^{\alpha}=e(i)$.

${ }^{2}$ The idea behind the model is the following. By being pessimistic,we consider that all delayed activities are planned according to realization and if $D(p)-D\left(p_{\mid \varepsilon}, r_{\mid N \backslash \varepsilon}\right)<0$, i.e. the delayed activities could bring delay to the project on their own, then the reward function for the expedited activities changes to $\tilde{R}(t)=\left(R\left(t+D(p)-D\left(p_{\mid \varepsilon}, r_{\mid N \backslash \varepsilon}\right)\right)\right)_{+}$. In this way, the expedited activities need to allocate $\tilde{R}\left(D\left(p_{\mid \varepsilon}, r_{\mid N \backslash \mathcal{E}}\right)-D(r)\right)$ among themselves. To solve this allocation problem, the ideas behind bankruptcy games are followed taking into account the levels of expedition.
} 
where $w_{z}^{k}(S)$ represents the part of the contribution to the total reward $F^{k}$ that players in $S$ maximally would have to concede to players in the paths corresponding to $\bigcup_{l=1}^{k} J_{l}$ outside $S$, taking into account earlier concessions from the previous phases. Formally,

$$
w_{z}^{k}(S)=\min \left\{\sum_{i \in\left(\bigcup_{l=1}^{k} N_{J_{l}}\right) \backslash S} f_{i}^{z}-\sum_{l=1}^{k-1} w_{z}^{l}(S), F^{k}\right\}
$$

for all $k \in\{1, \ldots, g\}$, where $N_{J_{l}}=\bigcup_{\alpha \in J_{l}} N_{\alpha}$. Note that $w_{z}^{k}$ is non-negative. Moreover, $v_{z}(N)$ equals the total expedition of the project since $w_{z}^{k}(N)=0$ for any $k \in\{1, \ldots, g\}$.

Example 3.4. Consider the project problem $\left(\left\{N_{1}, N_{2}, N_{3}, N_{4}\right\}, p, r, R\right)$ in Example 3.1. Recall that $N_{1}=$ $\{\mathrm{A}\}, N_{2}=\{\mathrm{B}\}, N_{3}=\{\mathrm{C}, \mathrm{D}\}, N_{4}=\{\mathrm{E}\} ; p(\mathrm{~A})=21, p(\mathrm{~B})=19, p(\mathrm{C})=2, p(\mathrm{D})=16, p(\mathrm{E})=17 ; r(\mathrm{~A})=14$, $r(\mathrm{~B})=15, r(\mathrm{C})=7, r(\mathrm{D})=6, r(\mathrm{E})=14 ;$ and $R(t)=\left\{\begin{array}{ll}-20 t^{2} & \text { if } t \leq 0, \\ t^{4} & \text { if } 0<t \leq 4, \\ t^{2}+240 & \text { if } t>4 .\end{array}\right.$ The project is represented in Figure 2.

In this project problem $D(p)=21$ and $D(r)=15$, therefore there is a total expedition of $D(p)-D(r)=6$ and a reward of $R(6)=276$. Besides,

$$
\begin{aligned}
& d(\mathrm{~A})=0, d(\mathrm{~B})=0, d(\mathrm{C})=5, d(\mathrm{D})=0 \text { and } d(\mathrm{E})=0 ; \\
& e(\mathrm{~A})=7, e(\mathrm{~B})=4, e(\mathrm{C})=0, e(\mathrm{D})=10 \text { and } e(\mathrm{E})=3 ; \\
& \operatorname{rslack}\left(N_{1}, p, r\right)=0-0=0, \operatorname{rslack}\left(N_{2}, p, r\right)=2-0=2, \\
& \operatorname{rslack}\left(N_{3}, p, r\right)=3-5=-2, \operatorname{and} \operatorname{rslack}\left(N_{4}, p, r\right)=4-0=4 ; \\
& J_{1}=\{1,3\}, J_{2}=\{2\}, \text { and } J_{3}=\{4\} ; \\
& F^{1}=R\left(\operatorname{rslack}\left(J_{2}\right)\right)-R\left(\operatorname{rslack}\left(J_{1}\right)\right)=R(2)-R(0)=16, \\
& F^{2}=R\left(\operatorname{rslack}\left(J_{3}\right)\right)-R\left(\operatorname{rslack}\left(J_{2}\right)\right)=R(4)-R(2)=240, \text { and } \\
& F^{3}=R(D(p)-D(r))-R\left(\operatorname{rslack}\left(J_{3}\right)\right)=R(6)-R(4)=20 .
\end{aligned}
$$

For the computation of $\left(N, v_{z}\right)$ we use the serial surplus sharing mechanism. Associated to each path $N_{\alpha}$ we have the surplus sharing problem:

$$
\begin{aligned}
& \left(N_{1}, p^{1}, R^{1}\right): N_{1}=\{\mathrm{A}\}, \quad p^{1}=(7), \quad R^{1}(t)=\left\{\begin{array}{ll}
R(t) & \text { if } t \leq 0, \\
0 & \text { if } t>0
\end{array} \quad \text { and } \quad z^{1}=(289) ;\right. \\
& \left(N_{2}, p^{2}, R^{2}\right): N_{2}=\{\mathrm{B}\}, \quad p^{2}=(4), \quad R^{2}(t)=\left\{\begin{array}{ll}
R(t+2)-R(2) & \text { if if } t \geq 0, \\
0 & \text { if } t>0,
\end{array} \text { and } \quad z^{2}=(260) ;\right. \\
& \left(N_{3}, p^{3}, R^{3}\right): \quad N_{3}=\{\mathrm{C}, \mathrm{D}\}, p^{3}=(0,10), R^{3}(t)=\left\{\begin{array}{ll}
R(t) & \text { if } t \leq 0, \\
0 & \text { if } t>0
\end{array} \quad \text { and } \quad z^{3}=(0,340) ;\right. \\
& \left(N_{4}, p^{4}, R^{4}\right): \quad N_{4}=\{\mathrm{E}\}, \quad p^{4}=(3), \quad R^{4}(t)=\left\{\begin{array}{ll}
R(t+4)-R(4) & \text { if if } t \geq 0, \\
0 & \text { if } t>0,
\end{array} \quad \text { and } \quad z^{4}=(33) ;\right.
\end{aligned}
$$

which gives $f^{z}=(289,260,0,340,33)$. Below, the computation of $v_{z}(\{\mathrm{~A}, \mathrm{~B}, \mathrm{D}\})$ is explained.

$$
w_{z}^{1}(\{\mathrm{~A}, \mathrm{~B}, \mathrm{D}\})=\min \left\{f_{\mathrm{C}}^{z}, F^{1}\right\}=\min \{0,16\}=0,
$$




$$
\begin{aligned}
& w_{z}^{2}(\{\mathrm{~A}, \mathrm{~B}, \mathrm{D}\})=\min \left\{f_{\mathrm{C}}^{z}-w_{z}^{1}(\{\mathrm{~A}, \mathrm{~B}, \mathrm{D}\}), F^{2}\right\}=\min \{0-0,240\}=0, \\
& w_{z}^{3}(\{\mathrm{~A}, \mathrm{~B}, \mathrm{D}\})=\min \left\{f_{\mathrm{C}}^{z}+f_{\mathrm{E}}^{z}-w_{z}^{1}(\{\mathrm{~A}, \mathrm{~B}, \mathrm{D}\})-w_{z}^{2}(\{\mathrm{~A}, \mathrm{~B}, \mathrm{D}\}), F^{3}\right\}=\min \{0+33-0-0,20\}=20,
\end{aligned}
$$

and therefore

$$
\begin{aligned}
v_{z}(\{\mathrm{~A}, \mathrm{~B}, \mathrm{D}\}) & =\left(F^{1}-w_{z}^{1}(\{\mathrm{~A}, \mathrm{~B}, \mathrm{D}\})\right)+\left(F^{2}-w_{z}^{2}(\{\mathrm{~A}, \mathrm{~B}, \mathrm{D}\})\right)+\left(F^{3}-w_{z}^{3}(\{\mathrm{~A}, \mathrm{~B}, \mathrm{D}\})\right) \\
& =(16-0)+(240-0)+(20-20)=256 .
\end{aligned}
$$

\begin{tabular}{|c|c|c|c|c|c|c|c|c|c|c|c|c|c|c|c|}
\hline$S$ & $\{\mathrm{~A}\}$ & $\{B\}$ & $\{C\}$ & $\{\mathrm{D}\}$ & $\{\mathrm{E}\}$ & $\{\mathrm{A}, \mathrm{B}\}$ & $\{\mathrm{A}, \mathrm{C}\}$ & $\{\mathrm{A}, \mathrm{D}$ & $\{\mathrm{A}, \mathrm{E}\}$ & $\{\mathrm{B}, \mathrm{C}\}$ & $\{\mathrm{B}, \mathrm{D}\}$ & $\{\mathrm{B}, \mathrm{E}$ & a $\}$ \{C,D $\}$ & $\{\mathrm{C}, \mathrm{E}\}$ & $\{\mathrm{D}, \mathrm{E}\}$ \\
\hline$v_{z}(S)$ & 0 & 0 & 0 & 0 & 0 & 0 & 0 & 16 & 0 & 0 & 0 & 0 & 0 & 0 & 0 \\
\hline$S$ & $\{\mathrm{~A}, \mathrm{~B}$ & & $\{\mathrm{A}, \mathrm{B}, \mathrm{I}$ & & $\mathrm{A}, \mathrm{B}, \mathrm{E}\}$ & $\{\mathrm{A}, \mathrm{C}$, & D $\}\{\mathrm{A}$ & $, \mathrm{C}, \mathrm{E}\}$ & $\{\mathrm{A}, \mathrm{D}, \mathrm{E}\}$ & $\{\mathrm{B}, \mathrm{C}, \mathrm{D}$ & $\{\mathrm{B}, \mathrm{C}$ & $, \mathrm{E}\}$ & $\{\mathrm{B}, \mathrm{D}, \mathrm{E}\}$ & $\{\mathrm{C}, \mathrm{D}, \mathrm{E}\}$ & \\
\hline$v_{z}(S)$ & 0 & & 256 & & 0 & 16 & & 0 & 16 & 0 & 0 & & 0 & 0 & \\
\hline$S$ & $\{\mathrm{~A}, \mathrm{~B}$ & $, C, D\}$ & $\{\mathrm{A}, \mathrm{I}$ & $B, C, E$ & \}$\left\{\begin{array}{l}0,1 \\
0\end{array}\right.$ & $\mathrm{B}, \mathrm{D}, \mathrm{E}\}$ & $\{\mathrm{A}, \mathrm{C}, \mathrm{I}$ & $D, E\}$ & $\mathrm{B}, \mathrm{C}, \mathrm{D}, \mathrm{E}\}$ & $\mathrm{N}$ & & & & & \\
\hline$v_{z}(S)$ & & 56 & & 0 & & 276 & 16 & & 0 & 276 & & & & & \\
\hline
\end{tabular}

All coalitional values are given in Table 8.

Table 8: Coalitional values in Example 3.4.

It can be checked that the core of the game is

$$
\begin{array}{r}
\operatorname{Core}\left(v_{z}\right)=\operatorname{conv}\{(0,0,0,256,20),(0,0,0,276,0),(0,240,0,16,20),(0,260,0,16,0), \\
(256,0,0,0,20),(276,0,0,0,0),(16,240,0,0,20),(16,260,0,0,0)\} .
\end{array}
$$

Given a project problem $\left(\left\{N_{1}, \ldots, N_{m}\right\}, p, r, a, R\right)$ and a surplus sharing mechanism $z$, the corresponding game $\left(N, v_{z}\right)$ can be described as the maximum of as many bankruptcy games as levels of expedition in the project, where the bankruptcy problem associated to level of expedition $k \in\{1, \ldots, g\}$ is

$$
\left(N, E^{k}, c^{z, k}\right)
$$

with $E^{k}=R\left(\operatorname{rslack}\left(J_{k+1}\right)\right)$ if $k<g$ and $E^{g}=R(D(p)-D(r))$, and $c_{i}^{z, k}=f_{i}^{z}$ if $i \in \cup_{l=1}^{k} N_{J_{l}}$ and $c_{i}^{z, k}=0$ otherwise. Besides, it turns out that $\left(N, v_{z}\right)$ is convex.

Theorem 3.2. Let $\left(\left\{N_{1}, \ldots, N_{m}\right\}, p, r, a, R\right)$ be a project problem and let $z$ be a surplus sharing mechanism. Then,

$$
v_{z}(S)=\max _{k \in\{1, \ldots, g\}}\left\{v_{\left(N, E^{k}, c^{z, k}\right)}(S)\right\}
$$

for every $S \subset N$. 
Proof: Since $z$ is fixed, we denote $c^{z, k}$ by $c^{k}$. We proceed by induction on $g$. Let $g=1$ and $S \subset N$, then

$$
v_{z}(S)=F^{1}-w_{z}^{1}(S)=F^{1}-\min \left\{\sum_{i \in N \backslash S} f_{i}^{z}, F^{1}\right\}=\max \left\{F^{1}-\sum_{i \in N \backslash S} f_{i}^{z}, 0\right\}=v_{\left(N, E^{1}, c^{1}\right)}(S) .
$$

Next, assume that the result is satisfied for $1, \ldots, g-1$. Let $S \subset N$, then

$$
\begin{aligned}
& v_{z}(S)=\sum_{k=1}^{g}\left(F^{k}-w_{z}^{k}(S)\right) \\
& =\sum_{k=1}^{g} F^{k}-\sum_{k=1}^{g-1} w_{z}^{k}(S)-\min \left\{\sum_{i \in\left(\bigcup_{k=1}^{g} N_{J_{k}}\right) \backslash S} f_{i}^{z}-\sum_{k=1}^{g-1} w_{z}^{k}(S), F^{g}\right\} \\
& =\max \left\{\sum_{k=1}^{g} F^{k}-\sum_{i \in\left(\bigcup_{k=1}^{g} N_{J_{k}}\right) \backslash S} f_{i}^{z}, \sum_{k=1}^{g-1} F^{k}-\sum_{k=1}^{g-1} w_{z}^{k}(S)\right\} \\
& =\max \left\{\sum_{k=1}^{g} F^{k}-\sum_{i \in\left(\bigcup_{k=1}^{g} N_{J_{k}}\right) \backslash S} f_{i}^{z}, \max _{k \in\{1, \ldots, g-1\}}\left\{v_{\left(N, E^{k}, c^{k}\right)}(S)\right\}\right\} \\
& =\max \left\{\left(\sum_{k=1}^{g} F^{k}-\sum_{i \in\left(\bigcup_{k=1}^{g} N_{J_{k}}\right) \backslash S} f_{i}^{z}\right)_{+} \max _{k \in\{1, \ldots, g-1\}}\left\{v_{\left(N, E^{k}, c^{k}\right)}(S)\right\}\right\} \\
& =\max \left\{\left(E^{g}-\sum_{i \in N \backslash S} c_{i}^{g}\right)_{+} \max _{k \in\{1, \ldots, g-1\}}\left\{v_{\left(N, E^{k}, c^{k}\right)}(S)\right\}\right\} \\
& =\max \left\{v_{\left(N, E^{g}, c^{g}\right)}(S), \max _{k \in\{1, \ldots, g-1\}}\left\{v_{\left(N, E^{k}, c^{k}\right)}(S)\right\}\right\} \\
& =\max _{k \in\{1, \ldots, g\}}\left\{v_{\left(N, E^{k}, c^{k}\right)}(S)\right\}
\end{aligned}
$$

where the fourth equality follows by induction, the fifth one is a consequence of $\max _{k \in\{1, \ldots, g-1\}}\left\{v_{\left(N, E^{k}, c^{k}\right)}(S)\right\}$ $\geq 0$, and the sixth one follows because $\sum_{k=1}^{g} F^{k}=R(D(p)-D(r))=E^{g}$ and because, by definition of $c^{g}$, we have $c_{i}^{g}=f_{i}^{z}$ if $i \in \bigcup_{k=1}^{g} N_{J_{k}}$ and $c_{i}^{g}=0$ otherwise.

The next example illustrates the result in Theorem 3.2.

Example 3.5. Consider the expedited project game in Example 3.4. Associated to each level of expedition $J_{k}$ we have a bankruptcy problem $\left(N, E^{k}, c^{z, k}\right)$ :

$$
\begin{array}{ll}
E^{1}=R\left(\operatorname{slack}\left(J_{2}\right)\right)=R(2)=16, & c^{z, 1}=\left(f_{\mathrm{A}}^{z}, 0, f_{\mathrm{C}}^{z}, f_{\mathrm{D}}^{z}, 0\right)=(289,0,0,340,0), \\
E^{2}=R\left(\operatorname{slack}\left(J_{3}\right)\right)=R(4)=256, & c^{z, 2}=\left(f_{\mathrm{A}}^{z}, f_{\mathrm{B}}^{z}, f_{\mathrm{C}}^{z}, f_{\mathrm{D}}^{z}, 0\right)=(289,260,0,340,0), \\
E^{3}=R(D(p)-D(r))=R(6)=276, & c^{z, 3}=\left(f_{\mathrm{A}}^{z}, f_{\mathrm{B}}^{z}, f_{\mathrm{C}}^{z}, f_{\mathrm{D}}^{z}, f_{\mathrm{E}}^{z}\right)=(289,260,0,340,33) .
\end{array}
$$

Table 9 gives the values of the corresponding bankruptcy games and expedited project game. 


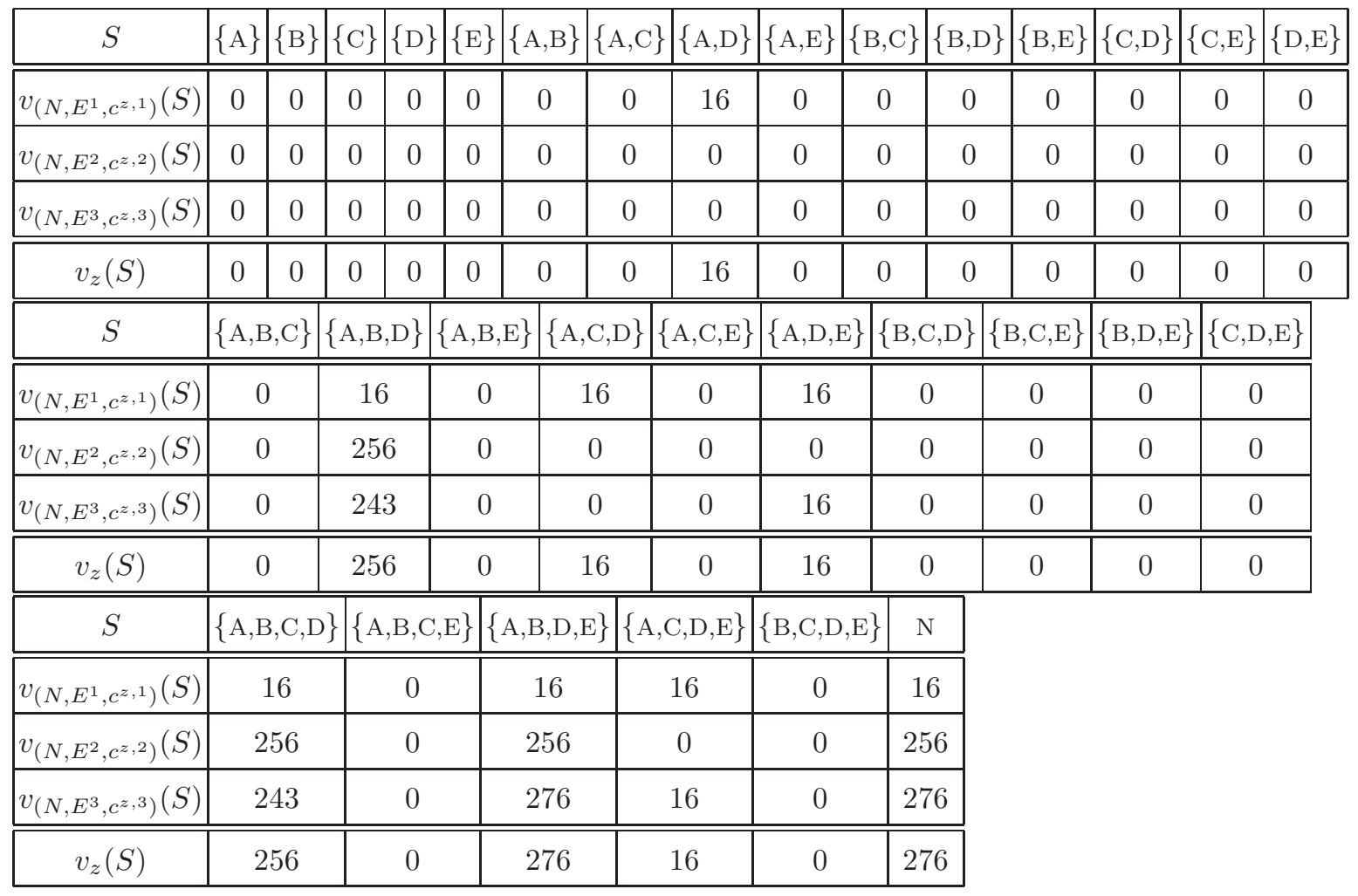

Table 9: Values of the bankruptcy games and expedited part of the project game in Example 3.5.

Before showing the convexity of $\left(N, v_{z}\right)$, we need to introduce some notation and provide a technical result. Note that, by definition of $c^{z, k}$, we have that $c_{i}^{z, k^{\prime}} \leq c_{i}^{z, k}$ for every $i \in N$ and every $k^{\prime} \leq k$. For $U \subset N$, let $\hat{k}\left(U, v_{z}\right)$ denote the smallest index satisfying $v_{z}(U)=v_{\left(N, E^{\hat{k}\left(U, v_{z}\right)}, c^{\left.z, \hat{k}\left(U, v_{z}\right)\right)}\right.}(U)$, i.e.

$$
\hat{k}\left(U, v_{z}\right)=\min \left\{k \in\{1, \ldots, g\} \mid v_{z}(U)=v_{\left(N, E^{k}, c^{z, k}\right)}(U)\right\} .
$$

Lemma 3.3. Let $\left(\left\{N_{1}, \ldots, N_{m}\right\}, p, r, a, R\right)$ be a project problem and let $z$ be a surplus sharing mechanism. Then, $\hat{k}\left(S, v_{z}\right) \leq \hat{k}\left(T, v_{z}\right)$ for every $S \subset T \subset N$.

Proof: Since $z$ is fixed, we denote $c^{z, k}$ by $c^{k}$. By Theorem 3.2 it follows

$v_{z}(T)=\max _{k \in\{1, \ldots, g\}}\left\{v_{\left(N, E^{k}, c^{k}\right)}(T)\right\}=\max _{k \in\{1, \ldots, g\}}\left\{\left(E^{k}-\sum_{j \in N \backslash T} c_{j}^{k}\right)_{+}\right\}=\max _{k \in\{1, \ldots, g\}}\left\{\left(E^{k}-\sum_{j \in N \backslash S} c_{j}^{k}+\sum_{j \in T \backslash S} c_{j}^{k}\right)_{+}\right\}$

for $T \subset N$ and $S \subset T$.

We proceed by contradiction. Assume that $\hat{k}\left(S, v_{z}\right)>\hat{k}\left(T, v_{z}\right) \geq 1$, then

$$
v_{z}(S)=v_{\left(N, E^{\hat{k}\left(S, v_{z}\right)}, c^{\hat{k}\left(S, v_{z}\right)}\right)}(S)>v_{\left(N, E^{1}, c^{1}\right)}(S) \geq 0
$$

and

$$
v_{z}(T)=v_{\left(N, E^{\hat{k}\left(T, v_{z}\right)}, c^{\hat{k}\left(T, v_{z}\right)}\right)}(T)
$$




$$
\begin{aligned}
& =\left(E^{\hat{k}\left(T, v_{z}\right)}-\sum_{j \in N \backslash T} c_{j}^{\hat{k}\left(T, v_{z}\right)}\right)_{+} \\
& =\left(E^{\hat{k}\left(T, v_{z}\right)}-\sum_{j \in N \backslash S} c_{j}^{\hat{k}\left(T, v_{z}\right)}+\sum_{j \in T \backslash S} c_{j}^{\hat{k}\left(T, v_{z}\right)}\right)_{+} \\
& \leq\left(E^{\hat{k}\left(T, v_{z}\right)}-\sum_{j \in N \backslash S} c_{j}^{\hat{k}\left(T, v_{z}\right)}\right)_{+}+\sum_{j \in T \backslash S} c_{j}^{\hat{k}\left(T, v_{z}\right)} \\
& <E^{\hat{k}\left(S, v_{z}\right)}-\sum_{j \in N \backslash S} c_{j}^{\hat{k}\left(S, v_{z}\right)}+\sum_{j \in T \backslash S} c_{j}^{\hat{k}\left(T, v_{z}\right)} \\
& \leq E^{\hat{k}\left(S, v_{z}\right)}-\sum_{j \in N \backslash S} c_{j}^{\hat{k}\left(S, v_{z}\right)}+\sum_{j \in T \backslash S} c_{j}^{\hat{k}\left(S, v_{z}\right)} \\
& =\left(E^{\hat{k}\left(S, v_{z}\right)}-\sum_{j \in N \backslash T} c_{j}^{\hat{k}\left(S, v_{z}\right)}\right)_{+} \\
& =v_{\left(N, E^{\hat{k}(S, v z)}, c^{\hat{k}\left(S, v_{z}\right)}\right)}(T)
\end{aligned}
$$

which contradicts the definition of $\hat{k}\left(T, v_{z}\right)$. Here, the first and second equalities follow by definition of $\hat{k}\left(T, v_{z}\right)$ and $v_{\left(N, E^{\hat{k}\left(T, v_{z}\right)}, c^{\hat{k}\left(T, v_{z}\right)}\right)}(T)$, respectively. The second inequality follows because $\hat{k}\left(T, v_{z}\right)<\hat{k}\left(S, v_{z}\right)$, and then $v_{z}(S)=v_{\left(N, E^{\hat{k}\left(S, v_{z}\right)}, \hat{c}^{\hat{k}\left(S, v_{z}\right)}\right)}(S)>v_{\left(N, E^{\hat{k}\left(T, v_{z}\right)}, c^{\hat{k}\left(T, v_{z}\right)}\right)}(S)$ by definition of $\hat{k}\left(S, v_{z}\right)$, together with $v_{z}(S)>0$. The last inequality follows because $\hat{k}\left(T, v_{z}\right)<\hat{k}\left(S, v_{z}\right)$, and then $c^{\hat{k}\left(T, v_{z}\right)} \leq c^{\hat{k}\left(S, v_{z}\right)}$ by definition of $c^{k}$. The last equality is a consequence of $E^{\hat{k}\left(S, v_{z}\right)}-\sum_{j \in N \backslash S} c_{j}^{\hat{k}\left(S, v_{z}\right)} \geq 0$ and $c^{\hat{k}\left(S, v_{z}\right)} \geq 0$.

Convexity of $\left(N, v_{z}\right)$ can be shown following the same lines as in the proof of Theorem 4.2 in EstévezFernández et al. (2007). We have decided to provide this new proof since it is more understandable and less technical than that in Estévez-Fernández et al. (2007). The simplicity of this new proof is rooted in both the relation between the expedited part of a project game and a number of related bankruptcy games, and the special structure of the claims of the related bankruptcy games.

Theorem 3.4. Let $\left(\left\{N_{1}, \ldots, N_{m}\right\}, p, r, a, R\right)$ be a project problem and let $z$ be a surplus sharing mechanism. Then, $\left(N, v_{z}\right)$ is convex.

Proof: Let $\left(\left\{N_{1}, \ldots, N_{m}\right\}, p, r, R\right)$ be an expedited project problem, let $z$ be a cost sharing mechanism, and let $\left(N, v_{z}\right)$ be the expedited part of the project game. Since $z$ is fixed, we denote $c^{z, k}$ by $c^{k}$. Let $i \in N$ and $S \subset T \subset N \backslash\{i\}$, we have to show that $v_{z}(S \cup\{i\})-v_{z}(S) \leq v_{z}(T \cup\{i\})-v_{z}(T)$.

Note that $(N, v z)$ satisfies monotonicity, i.e. $v_{z}(S) \leq v_{z}(T)$ for every $S \subset T \subset N$, since bankruptcy games are monotonic together with Theorem 3.2. Therefore, if $v_{z}(S \cup\{i\})-v_{z}(S)=0$ or $v_{z}(S)=v_{z}(T)$, then the condition is satisfied by monotonicity of $\left(N, v_{z}\right)$. We can then assume without loss of generality that $v_{z}(S \cup\{i\})>v_{z}(S)$ and $v_{z}(T)>v_{z}(S)$ by monotonicity of $\left(N, v_{z}\right)$. Note that then $v_{z}(S \cup\{i\})>0$ and $v_{z}(T)>0$ since $v_{z}$ is nonnegative. We distinguish between two cases. 
Case 1: $\hat{k}\left(S \cup\{i\}, v_{z}\right) \leq \hat{k}\left(T, v_{z}\right)$. Then,

$$
\begin{aligned}
v_{z}(S \cup\{i\})-v_{z}(S) & =E^{\hat{k}\left(S \cup\{i\}, v_{z}\right)}-\sum_{j \in N \backslash S} c_{j}^{\hat{k}\left(S \cup\{i\}, v_{z}\right)}+c_{i}^{\hat{k}\left(S \cup\{i\}, v_{z}\right)}-\left(E^{\hat{k}\left(S, v_{z}\right)}-\sum_{j \in N \backslash S} c_{j}^{\hat{k}\left(S, v_{z}\right)}\right)_{+} \\
& \leq E^{\hat{k}\left(S \cup\{i\}, v_{z}\right)}-\sum_{j \in N \backslash S} c_{j}^{\hat{k}\left(S \cup\{i\}, v_{z}\right)}+c_{i}^{\hat{k}\left(S \cup\{i\}, v_{z}\right)}-\left(E^{\hat{k}\left(S \cup\{i\}, v_{z}\right)}-c_{j}^{\hat{k}\left(S \cup\{i\}, v_{z}\right)}\right)_{+} \\
& \leq c_{i}^{\hat{k}\left(S \cup\{i\}, v_{z}\right)} \\
& \leq c_{i}^{\hat{k}\left(T, v_{z}\right)} \\
& =E^{\hat{k}\left(T, v_{z}\right)}-\sum_{j \in N \backslash T} c_{j}^{\hat{k}\left(T, v_{z}\right)}+c_{i}^{\hat{k}\left(T, v_{z}\right)}-E^{\hat{k}\left(T, v_{z}\right)}+\sum_{j \in N \backslash T} c_{j}^{\hat{k}\left(T, v_{z}\right)} \\
& \leq E^{\hat{k}\left(T \cup\{i\}, v_{z}\right)}-\sum_{j \in N \backslash T} c_{j}^{\hat{k}\left(T \cup\{i\}, v_{z}\right)}+c_{i}^{\hat{k}\left(T \cup\{i\}, v_{z}\right)}-\left(E^{\hat{k}\left(T, v_{z}\right)}-\sum_{j \in N \backslash T} c_{j}^{\hat{k}\left(T, v_{z}\right)}\right) \\
& =v_{z}(T \cup\{i\})-v_{z}(T)
\end{aligned}
$$

where the first equality is a direct consequence of the definition of $\hat{k}$ applied to $S \cup\{i\}$ and $S$ and because $v(S \cup\{i\})>v(S)(\geq 0)$ by assumption; the first inequality follows by definition of $\hat{k}$ applied to coalition $S$; the second inequality is a direct consequence of $(x)_{+}=\max \{0, x\}$; the third inequality follows because $\hat{k}\left(S \cup\{i\}, v_{z}\right) \leq \hat{k}\left(T, v_{z}\right)$ and by definition of $c^{k}$ we have $c^{\hat{k}\left(S \cup\{i\}, v_{z}\right)} \leq c^{\hat{k}\left(T, v_{z}\right)}$; the last inequality follows by definition of $\hat{k}$ applied to coalition $T \cup\{i\}$ and $v_{z}(T \cup\{i\}) \geq v_{z}(T)>0$; and the last equality is a direct consequence of the definition of $\hat{k}$ and $v_{z}(T \cup\{i\}) \geq v_{z}(T)>v_{z}(S)(\geq 0)$ by assumption.

Case 2: $\hat{k}\left(S \cup\{i\}, v_{z}\right)>\hat{k}\left(T, v_{z}\right)$. In this case we show that the equivalent condition $v_{z}(S \cup\{i\})+v_{z}(T) \leq$ $v_{z}(T \cup\{i\})+v_{z}(S)$ is satisfied.

$$
\begin{aligned}
v_{z}(S \cup\{i\})+v_{z}(T) & =E^{\hat{k}\left(S \cup\{i\}, v_{z}\right)}-\sum_{j \in N \backslash(S \cup\{i\})} c_{j}^{\hat{k}\left(S \cup\{i\}, v_{z}\right)}+E^{\hat{k}\left(T, v_{z}\right)}-\sum_{j \in N \backslash T} c_{j}^{\hat{k}_{j}\left(T, v_{z}\right)} \\
& =E^{\hat{k}\left(S \cup\{i\}, v_{z}\right)}-\sum_{j \in N \backslash(S \cup\{i\})} c_{j}^{\hat{k}\left(S \cup\{i\}, v_{z}\right)}+E^{\hat{k}\left(T, v_{z}\right)}-\sum_{j \in N \backslash S} c_{j}^{\hat{k}\left(T, v_{z}\right)}+\sum_{j \in T \backslash S} c_{j}^{\hat{k}\left(T, v_{z}\right)} \\
& \leq E^{\hat{k}\left(S \cup\{i\}, v_{z}\right)}-\sum_{j \in N \backslash(S \cup\{i\})} c_{j}^{\hat{k}\left(S \cup\{i\}, v_{z}\right)}+\left(E^{\hat{k}\left(T, v_{z}\right)}-\sum_{j \in N \backslash S} c_{j}^{\hat{k}\left(T, v_{z}\right)}\right)_{+}+\sum_{j \in T \backslash S} c_{j}^{\hat{k}\left(T, v_{z}\right)} \\
& \leq E^{\hat{k}\left(S \cup\{i\}, v_{z}\right)}-\sum_{j \in N \backslash(S \cup\{i\})} c_{j}^{\hat{k}\left(S \cup\{i\}, v_{z}\right)}+\left(E^{\hat{k}\left(S, v_{z}\right)}-\sum_{j \in N \backslash S} c_{j}^{\hat{k}\left(S, v_{z}\right)}\right)_{+}+\sum_{j \in T \backslash S} c_{j}^{\hat{k}\left(T, v_{z}\right)} \\
& \leq E^{\hat{k}\left(S \cup\{i\}, v_{z}\right)}-\sum_{j \in N \backslash(S \cup\{i\})} c_{j}^{\hat{k}\left(S \cup\{i\}, v_{z}\right)}+\left(E^{\hat{k}\left(S, v_{z}\right)}-\sum_{j \in N \backslash S} c_{j}^{\hat{k}\left(S, v_{z}\right)}\right)_{+} \sum_{j \in T \backslash S} c_{j}^{\hat{k}\left(S \cup\{i\}, v_{z}\right)} \\
& =E^{\hat{k}\left(S \cup\{i\}, v_{z}\right)}-\sum_{j \in N \backslash(T \cup\{i\})} c_{j}^{\hat{k}\left(S \cup\{i\}, v_{z}\right)}+\left(E^{\hat{k}\left(S, v_{z}\right)}-\sum_{j \in N \backslash S} c_{j}^{\hat{k}\left(S, v_{z}\right)}\right)_{+} \\
& \leq E^{\hat{k}\left(T \cup\{i\}, v_{z}\right)}-\sum_{j \in N \backslash(T \cup\{i\})} c_{j}^{\hat{k}\left(T \cup\{i\}, v_{z}\right)}+\left(E^{\hat{k}\left(S, v_{z}\right)}-\sum_{j \in N \backslash S} c_{j}^{\hat{k}\left(S, v_{z}\right)}\right)_{+}
\end{aligned}
$$




$$
=v_{z}(T \cup\{i\})+v_{z}(S)
$$

where the first equality is a direct consequence of the definition of $\hat{k}$ applied to $S \cup\{i\}$ and $T$ together with the assumption $v_{z}(S \cup\{i\})>v_{z}(S)(\geq 0)$ and $v_{z}(T)>v_{z}(S)(\geq 0)$; the second inequality follows by definition of $\hat{k}$ applied to $S$; the third inequality is a direct consequence of $\hat{k}\left(T, v_{z}\right)<\hat{k}\left(S \cup\{i\}, v_{z}\right)$ and by definition

of $c^{k}$ we have $c^{\hat{k}\left(T, v_{z}\right)} \leq c^{\hat{k}\left(S \cup\{i\}, v_{z}\right)}$; the last inequality follows by definition of $\hat{k}$ applied to coalition $T \cup\{i\}$ together with $v_{z}(T \cup\{i\}) \geq v_{z}(T)>0$; finally, the last equality follows by definition of $\hat{k}$ together with $v_{z}(T \cup\{i\}) \geq v_{z}(T)(>0)$ by monotonicity of $v_{z}$.

\subsection{Project games}

Finally, we define the associated project game $\left(N, u_{y z}\right)$ by

$$
u_{y z}(S)= \begin{cases}-c_{y}(S), & \text { if } D\left(p_{\mid \mathcal{E} \backslash S}, r_{\mid N \backslash(\mathcal{E} \backslash S)}\right) \geq D(p) ; \\ v_{z}(S), & \text { if } D\left(p_{\mid \mathcal{E} \backslash S}, r_{\mid N \backslash(\mathcal{E} \backslash S)}\right)<D(p) .\end{cases}
$$

for every $S \subset N$. Note that if the project has been delayed, then $u_{y z}=-c_{y}$ since $D\left(p_{\mid \mathcal{E} \backslash S}, r_{\mid N \backslash(\mathcal{E} \backslash S)}\right) \geq$ $D(r) \geq D(p)$ and therefore project games need not be convex (see Example 3.2).

As an illustrative example of the computation of project games, we compute the project game and its corresponding core for the project problem in Examples 3.1 and 3.4.

Example 3.6. Consider the project problem $\left(\left\{N_{1}, N_{2}, N_{3}, N_{4}\right\}, p, r, R\right)$ in Examples 3.1 and 3.4 which is represented in Figure 2.

For the computation of $\left(N, u_{y z}\right)$, we first compute $\left(N, c_{y}\right)$ and $\left(N, v_{z}\right)$. In order to compute $\left(N, c_{y}\right)$, note that only activity $\mathrm{C}$, which is in path $N_{3}$, has been delayed and hence $y^{1}=(0), y^{2}=(0), y^{3}=(-R(-2), 0)=$ $(80,0)$ and $y^{4}=(0)$. Recall that we have used the serial surplus sharing mechanism for the computation of $\left(N, v_{z}\right)$ (see Example 3.4). All coalitional values are given in Table 10.

It can be checked that the core of the game is

$$
\begin{aligned}
\operatorname{Core}\left(u_{y z}\right)=\operatorname{conv}\{ & (0,0,0,256,20),(0,0,0,276,0),(0,240,0,16,20),(0,260,0,16,0), \\
& (256,0,0,0,20),(276,0,0,0,0),(16,240,0,0,20),(16,260,0,0,0), \\
& (0,0,-80,336,20),(0,0,-80,356,0),(0,240,-80,96,20),(0,260,-80,96,0), \\
& (256,0,-80,80,20),(276,0,-80,80,0),(16,240,-80,80,20),(16,260,-80,80,0)\} .
\end{aligned}
$$

The following example illustrates how availabilities of the activities are taken into account when solving a project problem. 


\begin{tabular}{|c|c|c|c|c|c|c|c|c|c|c|c|c|c|c|c|}
\hline$S$ & $\{\mathrm{~A}\}$ & $\{\mathrm{B}\}$ & $\{\mathrm{C}\}$ & $\{\mathrm{D}\}$ & $\{\mathrm{E}\}$ & $\{\mathrm{A}, \mathrm{B}\}$ & $\{\mathrm{A}, \mathrm{C}\}$ & $\{\mathrm{A}, \mathrm{D}\}$ & $\{\mathrm{A}, \mathrm{E}\}$ & $\{\mathrm{B}, \mathrm{C}\}$ & $\{\mathrm{B}, \mathrm{D}\}$ & $\{\mathrm{B}, \mathrm{E}\}$ & $\{\mathrm{C}, \mathrm{D}\}$ & $\{\mathrm{C}, \mathrm{E}\}$ & $\{\mathrm{D}, \mathrm{E}\}$ \\
\hline \hline$D\left(p_{|\varepsilon| S}, r_{\mid N \backslash(\varepsilon) S)}\right)$ & 23 & 23 & 23 & 21 & 23 & 23 & 23 & 19 & 23 & 23 & 21 & 23 & 21 & 23 & 21 \\
\hline$-c_{y}(S)$ & 0 & 0 & -80 & 0 & 0 & 0 & -80 & 0 & 0 & -80 & 0 & 0 & 0 & -80 & 0 \\
\hline$v_{z}(S)$ & 0 & 0 & 0 & 0 & 0 & 0 & 0 & 16 & 0 & 0 & 0 & 0 & 0 & 0 & 0 \\
\hline$u_{y z}(S)$ & 0 & 0 & -80 & 0 & 0 & 0 & -80 & 16 & 0 & -80 & 0 & 0 & 0 & -80 & 0 \\
\hline \hline$S$ & $\{\mathrm{~A}, \mathrm{~B}, \mathrm{C}\}$ & $\{\mathrm{A}, \mathrm{B}, \mathrm{D}\}$ & $\{\mathrm{A}, \mathrm{B}, \mathrm{E}\}$ & $\{\mathrm{A}, \mathrm{C}, \mathrm{D}\}$ & $\{\mathrm{A}, \mathrm{C}, \mathrm{E}\}$ & $\{\mathrm{A}, \mathrm{D}, \mathrm{E}\}$ & $\{\mathrm{B}, \mathrm{C}, \mathrm{D}\}$ & $\{\mathrm{B}, \mathrm{C}, \mathrm{E}\}$ & $\{\mathrm{B}, \mathrm{D}, \mathrm{E}\}$ & $\{\mathrm{C}, \mathrm{D}, \mathrm{E}\}$ \\
\hline \hline$D\left(p_{|\varepsilon| S}, r_{\mid M \backslash(\varepsilon \backslash S)}\right)$ & 23 & 17 & 23 & 19 & 23 & 19 & 21 & 23 & 21 & 21 \\
\hline$-c_{y}(S)$ & -80 & 0 & 0 & 0 & -80 & 0 & 0 & -80 & 0 & 0 \\
\hline$v_{z}(S)$ & 0 & 256 & 0 & 16 & 0 & 16 & 0 & 0 & 0 & 0 \\
\hline$u_{y z}(S)$ & -80 & 256 & 0 & 16 & -80 & 16 & 0 & -80 & 0 & 0 \\
\hline \hline$S$ & $\{\mathrm{~A}, \mathrm{~B}, \mathrm{C}, \mathrm{D}\}$ & $\{\mathrm{A}, \mathrm{B}, \mathrm{C}, \mathrm{E}\}$ & $\{\mathrm{A}, \mathrm{B}, \mathrm{D}, \mathrm{E}\}$ & $\{\mathrm{A}, \mathrm{C}, \mathrm{D}, \mathrm{E}\}$ & $\{\mathrm{B}, \mathrm{C}, \mathrm{D}, \mathrm{E}\}$ & $\mathrm{N}$ & & \\
\hline
\end{tabular}

Table 10: Computation of the project game in Example 3.6.

Example 3.7. Consider the project problem $\left(\left\{N_{1}, N_{2}\right\}, p, r, a, R\right)$ with $N_{1}=\{\mathrm{A}, \mathrm{C}\}$ and $N_{2}=\{\mathrm{B}, \mathrm{C}\}$; $p(\mathrm{~A})=15, p(\mathrm{~B})=10$, and $p(\mathrm{C})=8 ; r(\mathrm{~A})=7, r(\mathrm{~B})=6$, and $r(\mathrm{C})=12 ; a(\mathrm{~A})=0, a(\mathrm{~B})=0$, and $a(\mathrm{C})=7$; and $R(t)=\left\{\begin{array}{ll}t^{3}-100 & \text { if } t<0, \\ 0 & \text { if } t=0, \\ t^{3}+200 & \text { if } t>0,\end{array} \quad\right.$ represented in Figure 1.

Note that since activity $\mathrm{C}$ can only start 7 units of time before the planned starting time (i.e. at time 8), the expedition of $\mathrm{A}$ is not fully exploited. Hence, $D\left(N_{a}, r\right)=20$ since $\mathrm{C}$ cannot start before time 8 . In this project problem, $D(p)=23$ and $D(r)=20$, therefore there is a total expedition of $D(p)-D(r)=3$ and a reward of $R(6)=227$. Besides,

$$
\begin{aligned}
& d(\mathrm{~A})=0, d(\mathrm{~B})=0, \text { and } d(\mathrm{C})=4 ; \\
& e(\mathrm{~A})=8, e(\mathrm{~B})=4, \text { and } e(\mathrm{C})=0 ; \\
& \operatorname{rslack}\left(N_{1}, p, r\right)=0-4 \text { and } \operatorname{rslack}\left(N_{1}, p, r\right)=5-4=1 ; \\
& J_{1}=\{1\} \text { and } J_{2}=\{2\} \\
& F^{1}=R(1)-R(0)=201 \text { and } F^{2}=R(3)-R(1)=26 .
\end{aligned}
$$

For the computation of $\left(N, u_{y z}\right)$, we first compute $\left(N, c_{y}\right)$ and $\left(N, v_{z}\right)$.

Since only activity $\mathrm{C}$ has been delayed and $\mathrm{C}$ needs the expedition of A to compensate its own delay, 
we have that, for any cost sharing mechanism $y, c_{y}(S)=164$ if $S=\{\mathrm{C}\}$ or $S=\{\mathrm{B}, \mathrm{C}\}$ and $c_{y}(S)=0$ otherwise. For the computation of $\left(N, v_{z}\right)$ we use the serial surplus sharing mechanism. Associated to each path $N_{\alpha}$ we have the surplus problem:

$$
\begin{aligned}
\left(N_{1}, p^{1}, R^{1}\right): N_{1}=\{\mathrm{A}, \mathrm{C}\}, p^{1}(\mathrm{~A}) & =\min \{e(\mathrm{~A}), a(\mathrm{C})\}=\min \{8,7\}=7 \text { and } p^{1}(\mathrm{C})=0, \\
R^{1}(t) & =R(t) \text { for } t>0 \text { and } R^{1}(t)=0 \text { otherwise, and } z^{1}=(543,0) . \\
\left(N_{2}, p^{2}, R^{2}\right): N_{2}=\{\mathrm{B}, \mathrm{C}\}, p^{2}(\mathrm{~B}) & =\min \{e(\mathrm{~B}), a(\mathrm{C})\}=\min \{4,7\}=4 \text { and } p^{2}(\mathrm{C})=0, \\
R^{2}(t) & =R(t+1)-R(1) \text { for } t>0 \text { and } R^{2}(t)=0 \text { otherwise, and } z^{2}=(124,0) .
\end{aligned}
$$

All coalitional values are given in Table 11.

\begin{tabular}{|c|c|c|c|c|c|c|c|}
\hline$S$ & $\{\mathrm{~A}\}$ & $\{\mathrm{B}\}$ & $\{\mathrm{C}\}$ & $\{\mathrm{A}, \mathrm{B}\}$ & $\{\mathrm{A}, \mathrm{C}\}$ & $\{\mathrm{B}, \mathrm{C}\}$ & $\{\mathrm{A}, \mathrm{B}, \mathrm{C}\}$ \\
\hline \hline$D\left(p_{|\varepsilon| S}, r_{\mid N \backslash(\varepsilon \backslash S)}\right)$ & 22 & 27 & 27 & 20 & 22 & 27 & 20 \\
\hline$-c_{y}(S)$ & 0 & 0 & -164 & 0 & 0 & -164 & 0 \\
\hline$v_{z}(S)$ & 201 & 0 & 0 & 227 & 201 & 0 & 227 \\
\hline$u_{y z}(S)$ & 201 & 0 & -164 & 227 & 201 & -164 & 227 \\
\hline
\end{tabular}

Table 11: Computation of the project game in Example 3.7.

It can be checked that the core of the game is

$$
\operatorname{Core}\left(u_{y z}\right)=\operatorname{conv}\{(391,0,-164),(365,26,-164),(201,26,0),(227,0,0)\} \text {. }
$$

Theorem 3.5. Project games have a nonempty core.

Proof: Let $\left(\left\{N_{1}, \ldots, N_{m}\right\}, p, r, a, R\right)$ be a project problem, let $y$ and $z$ be a cost and a surplus sharing mechanism, respectively, and let $\left(N, u_{y z}\right)$ be the associated project game. We distinguish between two cases.

Case 1: $D(p) \leq D(r)$.

In this case, $D(p) \leq D(r) \leq D\left(p_{\mid \mathcal{E} \backslash S}, r_{\mid N \backslash(\mathcal{E} \backslash S)}\right)$ for every $S \subset N$, and therefore $u_{y z}(S)=-c_{y}(S)$ for every $S \subset N$. Then, $\left(N, u_{y z}\right)$ has a nonempty core by Theorem 3.1 .

Case 2: $D(p)>D(r)$.

In this case, $u_{y z}(N)=v_{z}(N)$ and $u_{y z}(S) \leq v_{z}(S)$ for every $S \subset N$. By Theorem 3.4, we know that $\left(N, v_{z}\right)$ is convex and therefore $\operatorname{Core}\left(v_{z}\right) \neq \emptyset$. Let $x \in \operatorname{Core}\left(v_{z}\right)$, then $\sum_{i \in N} x_{i}=v_{z}(N)=u_{y z}(N)$ and $\sum_{i \in S} x_{i} \geq v_{z}(S) \geq u_{y z}(S)$ for every $S \subset N$, and therefore $x \in \operatorname{Core}\left(u_{y z}\right)$.

We now show that the core of project games satisfies some basic and desirable properties for solutions of project problems. 
In many project problems the general manager of the project does not have legal authority to oblige delayed activities to compensate expedited activities for their contribution to decrease the total delay of the project. In this situation, a set-valued solution should satisfy: if the project is neither delayed, nor expedited, then there should be a solution in which nobody is neither punished, nor rewarded, i.e. if $D(r)=D(p)$, then the zero vector should be a possible solution; if the project is delayed, then there should be a solution in which the delayed activities pay exactly the total cost associated to the total delay, i.e. expedited activities are not compensated; if the project is expedited, then there should be a solution in which expedited activities get exactly the total reward associated to the total expedition, i.e. the delayed activities don't have to compensate expedited activities.

Let $\mathcal{D}$ be the set of delayed activities, i.e. $\mathcal{D}=\{i \in N \mid p(i)<r(i)\}$, and recall that $\mathcal{E}$ is the set of expedited activities, i.e. $\mathcal{E}=\{i \in N \mid p(i)>r(i)\}$.

Theorem 3.6. Let $\left(\left\{N_{1}, \ldots, N_{m}\right\}, p, r, a, R\right)$ be a project problem, let $y$ and $z$ be a cost and surplus sharing mechanism, respectively, and let $\left(N, u_{y z}\right)$ be the associated project game.

(i) If $D(p)<D(r)$, then there exist $x \in \operatorname{Core}\left(u_{y z}\right)$ such that $x_{i}=0$ for every $i \in N \backslash \mathcal{D}$.

(ii) If $D(p)=D(r)$, then $0 \in \operatorname{Core}\left(u_{y z}\right)$.

(iii) If $D(p)>D(r)$, then there exist $x \in \operatorname{Core}\left(u_{y z}\right)$ such that $x_{i}=0$ for every $i \in N \backslash \mathcal{E}$.

Proof: (i) If $D(p)<D(r)$, then $D(p)<D(r) \leq D\left(p_{\mid \mathcal{E} \backslash S}, r_{\mid N \backslash(\varepsilon \backslash S)}\right)$ for every $S \subset N$, and therefore $u_{y z}(S)=-c_{y}(S)$ for every $S \subset N$. Let $\hat{\alpha} \in\{1, \ldots, m\}$ be such that $D(r)=D\left(N_{\hat{\alpha}}, r\right)$, i.e. $N_{\hat{\alpha}}$ is responsible of the total delay of the project. Consider the taxation problem $\left(N, E^{\hat{\alpha}}, c^{\hat{\alpha}}\right)$ given by $E^{\hat{\alpha}}=$ $K\left(\sum_{i \in N_{\hat{\alpha}}} d(i)-\sum_{i \in N_{\hat{\alpha}}} e(i)-\operatorname{slack}\left(N_{\hat{\alpha}}, p\right)\right), c_{i}^{\hat{\alpha}}=y_{i}^{\hat{\alpha}}$ if $i \in N_{\hat{\alpha}}$ and $c_{i}^{\hat{\alpha}}=0$ if $i \in N \backslash N_{\hat{\alpha}}$. Note that $c_{i}^{\hat{\alpha}}=0$ for every $i \in N_{\hat{\alpha}} \backslash \mathcal{D}$. By the proof of Theorem 3.5, we know that $\operatorname{Core}\left(c_{\left(N, E^{\hat{\alpha}}, c^{\hat{\alpha}}\right)}\right) \subset \operatorname{Core}\left(c_{y}\right)$. Moreover, it is well known that any $x \in \operatorname{Core}\left(c_{\left(N, E^{\hat{\alpha}}, c^{\hat{\alpha}}\right)}\right)$ satisfies $0 \leq x \leq c^{\hat{\alpha}}$, and therefore $x_{i}=0$ for every $i \in N \backslash \mathcal{D}$.

(ii) If $D(p)=D(r)$, then $D(p)=D(r) \leq D\left(p_{\mid \mathcal{E} \backslash S}, r_{\mid N \backslash(\mathcal{E} \backslash S)}\right)$ for every $S \subset N$, and therefore $u_{y z}(S)=$ $-c_{y}(S) \leq 0$ for every $S \subset N$. Moreover, $u_{y z}(N)=0$ and then $0 \in \operatorname{Core}\left(u_{y z}\right)$.

(iii) If $D(p)>D(r)$, then $u_{y z}(N)=v_{z}(N)$ and $u_{y z}(S) \leq v_{z}(S)$ for every $S \subset N$. Then, Core $\left(v_{z}\right) \subset \operatorname{Core}\left(u_{y z}\right)$. Since $f_{i}^{z}=0$ for every $i \in N \backslash \mathcal{E}$, we have $v_{z}(S \cup\{i\})=v_{z}(S)$ for every $i \in N \backslash \mathcal{E}$ and therefore $x_{i}=0$ for every $x \in \operatorname{Core}\left(v_{z}\right)$ and $i \in N \backslash \mathcal{E}$. 
To finalize, we focus on project problems where the reward function is proportional to the expedition of the project. It turns out that the core of the game proposed in Estévez-Fernández et al. (2007) is always contained in the core of our project game. Recall that given a project problem $\left(\left\{N_{1}, \ldots, N_{m}\right\}, p, r, R\right)$ with $R(t)=\alpha t$ for every $t \in \mathbb{R}, \alpha \geq 0$, the corresponding game in Estévez-Fernández et al. (2007), $(N, \bar{u})$, is defined by

$$
\bar{u}(S)= \begin{cases}-\alpha \bar{c}(S) & \text { if } D\left(p_{\mid \varepsilon \backslash S}, r_{\mid N \backslash(\varepsilon \backslash S)}\right) \geq D(p), \\ \alpha \bar{v}(S) & \text { if } D\left(p_{\mid \varepsilon \backslash S}, r_{\mid N \backslash(\mathcal{E} \backslash S)}\right)<D(p),\end{cases}
$$

with

$$
\bar{c}(S)=\max _{\alpha \in \mathcal{P}(S)}\left\{\min \left\{\left(\sum_{i \in N_{\alpha} \cap S} d(i)-\sum_{i \in N_{\alpha} \cap S} e(i)\right)_{+},\left(\sum_{i \in N_{\alpha}} d(i)-\sum_{i \in N_{\alpha} \cap S} e(i)-\operatorname{slack}\left(N_{\alpha}, p\right)\right)_{+}\right\}\right\}
$$

and

$$
\bar{v}(S)=\sum_{k=1}^{g}\left(F^{k}-\bar{w}^{k}(S)\right)
$$

where $\bar{w}^{k}(S)=\min \left\{\sum_{i \in\left(\bigcup_{l=1}^{k} N_{J_{l}}\right) \backslash S} e(i)-\sum_{l=1}^{k-1} \bar{w}^{l}(S), F^{k}\right\}$.

Theorem 3.7. Let $\left(\left\{N_{1}, \ldots, N_{m}\right\}, p, r, R\right)$ be a project problem with $R$ proportional to the expedition time of the project and let $\left(N, u_{y^{s}} z^{s}\right)$ be the associated project game. Then, Core $(\bar{u}) \subset \operatorname{Core}\left(u_{y^{s}} z^{s}\right)$.

Proof: Due to the proportionality of the reward function, we can assume without loss of generality that $R(t)=t$ for every $t \in \mathbb{R}$. From the definition of $y^{s}$ and $z^{s}$ and the fact that all activities can start as soon as necessary, we have that $c_{y^{s}}$ and $v_{z^{s}}$ can be rewritten as

$$
c_{y^{s}}(S)=\max _{\alpha \in \mathcal{P}(S)}\left\{\min \left\{\sum_{i \in N_{\alpha} \cap S} d(i),\left(\sum_{i \in N_{\alpha}} d(i)-\sum_{i \in N_{\alpha} \cap S} e(i)-\operatorname{slack}\left(N_{\alpha}, p\right)\right)\right\}\right\}
$$

and

$$
v_{z^{s}}(S)=\sum_{k=1}^{g}\left(F^{k}-\bar{w}^{k}(S)\right)
$$

where $w_{z^{s}}^{k}(S)=\min \left\{\sum_{i \in\left(\bigcup_{l=1}^{k} N_{J_{l}}\right) \backslash S} e(i)-\sum_{l=1}^{k-1} w_{z^{s}}^{l}(S), F^{k}\right\}$.

It is easily seen that $\bar{w}^{k}=w_{z^{s}}^{k}$ for every $k \in\{1, \ldots, g\}, \bar{v}=v_{z^{s}}, \bar{u}(N)=u_{y^{s}} z^{s}(N)$ and $\bar{c} \leq c_{y^{s}}$. Therefore, $\bar{u} \geq u_{y^{s} z^{s}}$ with $\bar{u}(N)=u_{y^{s} z^{s}}(N)$ which implies Core $(\bar{u}) \subset \operatorname{Core}\left(u_{y^{s} z^{s}}\right)$.

\section{Final remarks}

We have generalized the work in Estévez-Fernández et al. (2007) by both considering non decreasing reward functions and by taking into account whether an activity can be started before its planned starting time. We 
have seen in Theorem 3.7 that the core of our game is bigger than the core of the game in Estévez-Fernández et al. (2007). Besides, the core of the game in Estévez-Fernández et al. (2007) does not need to satisfy the properties in Theorem 3.6 as illustrated in the following example.

Example 4.1. Consider the project problem $\left(\left\{N_{1}\right\}, p, r, R\right)$ with $N_{1}=\{\mathrm{A}, \mathrm{B}, \mathrm{C}\} ; p(\mathrm{~A})=7, p(\mathrm{~B})=8$, and $p(\mathrm{C})=10 ; r(\mathrm{~A})=8, r(\mathrm{~B})=11$, and $r(\mathrm{C})=9$; and $R(t)=t$. The project is represented in Figure 4 .

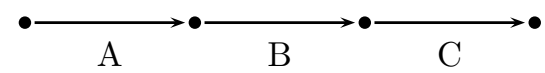

Figure 4: Representation of the project in Example 4.1.

In this problem, $D(p)-D(r)=-3 ; d(\mathrm{~A})=1, d(\mathrm{~B})=3$, and $d(\mathrm{C})=0 ; e(\mathrm{~A})=0, e(\mathrm{~B})=0$, and $e(\mathrm{C})=1$. The values of the game in Estévez-Fernández et al. (2007), (N, $\bar{u})$, and our project game are given in Table 12 . For the computation of $\left(N, u_{y z}\right)$ we have used $y_{i}(N, q, K)=q_{i}$ and $z_{i}(N, p, R)=p_{i}$.

\begin{tabular}{|c|c|c|c|c|c|c|c|}
\hline$S$ & $\{\mathrm{~A}\}$ & $\{\mathrm{B}\}$ & $\{\mathrm{C}\}$ & $\{\mathrm{A}, \mathrm{B}\}$ & $\{\mathrm{A}, \mathrm{C}\}$ & $\{\mathrm{B}, \mathrm{C}\}$ & $\mathrm{N}$ \\
\hline \hline $\bar{u}(S)$ & -1 & -3 & 0 & -4 & 0 & -2 & -3 \\
\hline$u_{y z}(S)$ & -1 & -3 & 0 & -4 & -1 & -3 & -3 \\
\hline
\end{tabular}

Table 12: Coalitional values in Example 4.1.

It can be checked that

$$
\operatorname{Core}(\bar{u})=\{(-1,-3,1)\}
$$

while

$$
\operatorname{Core}\left(u_{y z}\right)=\operatorname{conv}\{(-1,-3,1),(-1,-2,0),(0,-3,0)\} \text {. }
$$

We have used cooperative games to find solutions to project problems. The associated project game, in our opinion, provides an adequate thought experiment to evaluate coalitional influence and the core of this game provides a suitable answer to the allocation problem at hand.

Contrary to our focus on finding suitable allocations satisfying some basic properties, Castro, Gómez and Tejada (2007) concentrate on finding a game related to project problems satisfying some "desirable" properties. They put forward the properties of separability, non-manipulability by splitting, and independent slack and propose a cooperative game to share the total delay or expedition of a project satisfying these three properties. One can question the desirability of these three properties when we concentrate on the allocation of the rewards (or penalties) created by a project that has not performed as planned. For instance, the property of separability says that if a project can be decomposed in two different (sub)projects (i.e. if there is a node used by all paths in the project), then the associated game can be decomposed as the sum of 
the two games associated to the two corresponding (sub)projects. Note that the total reward of the project does not need to equal the sum of the rewards of the (sub)projects since we allow for non additive reward functions too. Hence, in our setting, separability does not need to be satisfied by project problems, let alone by the associated games.

In our opinion, it is not the properties of the game as a whole that are relevant, but rather the properties of the derived solutions (except of course from adequately modeling the coalitional possibilities).

As mentioned above, Castro, Gómez and Tejada (2007) define a cooperative game to share the total delay or expedition of a project. If one uses the core of this game to share the total reward in a project problem where the reward function is proportional to the total expedition or delay of the project, one encounters unwanted features in the allocations proposed by the core. It turns out that for projects in which the corresponding graph is a line, the game in Castro et al. (2007) is additive (i.e. the value of a coalition equals the sum of the individual values of its members). Therefore, the core of their game does not need to satisfy any of the properties proposed in Section 3.

Example 4.2. Consider the project problem $\left(\left\{N_{1}\right\}, p, r, R\right)$ with $N_{1}=\{\mathrm{A}, \mathrm{B}\}, p(\mathrm{~A})=10, p(\mathrm{~B})=15$, $r(\mathrm{~A})=13, r(\mathrm{~B})=12$, and $R(t)=t$. The project is represented in Figure 5.

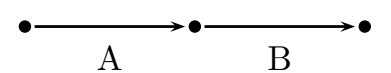

Figure 5: Representation of the project in Example 4.2.

In this problem, $D(p)-D(r)=0, d(\mathrm{~A})=3, d(\mathrm{~B})=0, e(\mathrm{~A})=0, e(\mathrm{~B})=3$, the values of their corresponding game $(N, v)$ are $v(\{\mathrm{~A}\})=-3, v(\{\mathrm{~B}\})=3, v(\{\mathrm{~A}, \mathrm{~B}\})=0$, and Core $(v)=\{(-3,3)\}$.

\section{References}

Atkinson, R. (1999), 'Project management: cost, time and quality, two best guesses and a phenomenon, its time to accept other success criteria', International Journal of Project Management 17, 337-342.

Bergantiños, G. and Sánchez, E. (2002), 'How to distribute costs associated with a delayed project', Annals of Operations Research 109, 159-174.

Borm, P., Hamers, H. and Hendrickx, R. (2001), 'Operations research games: A survey', Sociedad de Estadística e Investigación Operativa Top 9(2), 139-216.

Branzêi, R., Ferrari, G., Fragnelli, V. and Tijs, S. (2002), 'Two approaches to the problem of sharing delay costs in joint projects', Annals of Operations Research 109, 359-374. 
Castro, J., Gómez, D. and Tejada, J. (2007), 'A project game for pert networks', Operations Research Letters 35, 791-798.

Curiel, I. J., Maschler, M. and Tijs, S. (1987), 'Bankruptcy games', Zeitschrift für Operations Research 31, A $143-\mathrm{A} 159$.

Dayanand, N. and Padman, R. (2001), 'Project contracts and payment schedules: The client's problem', Management Science 47, 1654-1667.

Dorndorf, U., Pesch, E. and Phan-Huy, T. (2000), 'Time-orientebd ranch-and-bound algorithm for resourceconprojsectt rained scheduling with generalised precedence constraints', Management Science 46, 13651384.

Estévez-Fernández, A., Borm, P. and Hamers, H. (2007), 'Project games', International Journal of Game Theory 36, 149-176.

Gillies, D. (1953), Some theorems on n-person games, PhD thesis, Princeton, University Press Princeton, New Jersey.

Koster, M. (1999), Cost Sharing in Production Situations and Network Exploitation, PhD thesis, Tilburg University. I.S.B.N. 90-5668-057-9.

Möhring, R. H., Schulz, A. S., Stork, F. and Uetz, M. (2003), 'Solving project scheduling problems by minimum cut computations', Management Science 49, 330-350.

Moulin, H. (1987), 'Egalitarian-equivalent cost sharing of a public good', Econometrica 55, 963-976.

Moulin, H. and S. Shenker, S. (1992), 'Serial cost sharing', Econometrica 60, 1009-1037.

O’Neill, B. (1982), 'A problem of rights arbitration from the talmud', Mathematical Social Sciences 2, 345371 .

Pinto, J. and Slevin, D. (1988), 'Project success: Definitions and measurements techniques', Project Management Journal 19, 67-72.

Roberts, E. and Fusfeld, A. (1981), 'Staffing the innovative technology based organization', Sloan Management Review 22, 19-34.

Shapley, L. S. (1971), 'Cores of convex games', International Journal of Game Theory 1, 11-26.

Shenhar, A. and Dvi, D. (1996), 'Toward a typological theory of project management', Sloan Management Review 25, 607-632. 
Sherwin, C. and Isenson, R. (1967), 'Project hindsight: A defense department study of the utility of research', Science 156, 1571-1577.

Tubig, S. and Abeti, P. (1990), 'Variables influencing the performance of defense r\&d contractors', IEEE Transactions on Engineering Management 37, 22-30. 